University of Nebraska - Lincoln

DigitalCommons@University of Nebraska - Lincoln

\title{
Mapping biomass and stress in the Sierra Nevada using lidar and hyperspectral data fusion
}

\author{
Anu Swatantran \\ University of Maryland, aswatan@umd.edu \\ Ralph Dubayah \\ University of Maryland \\ Dar A. Roberts \\ University of California, Santa Barbara, dar@geog.ucsb.edu \\ Michelle Hofton \\ University of Maryland \\ J. Bryan Blair \\ Goddard Space Flight Center
}

Follow this and additional works at: https://digitalcommons.unl.edu/nasapub

Part of the Physical Sciences and Mathematics Commons

Swatantran, Anu; Dubayah, Ralph; Roberts, Dar A.; Hofton, Michelle; and Blair, J. Bryan, "Mapping biomass and stress in the Sierra Nevada using lidar and hyperspectral data fusion" (2011). NASA Publications. 93. https://digitalcommons.unl.edu/nasapub/93

This Article is brought to you for free and open access by the National Aeronautics and Space Administration at DigitalCommons@University of Nebraska - Lincoln. It has been accepted for inclusion in NASA Publications by an authorized administrator of DigitalCommons@University of Nebraska - Lincoln. 


\title{
Mapping biomass and stress in the Sierra Nevada using lidar and hyperspectral data fusion
}

\author{
Anu Swatantran a,*, Ralph Dubayah ${ }^{a}$, Dar Roberts ${ }^{b}$, Michelle Hofton ${ }^{a}$, J. Bryan Blair ${ }^{c}$ \\ a Department of Geography, University of Maryland, United States \\ b Department of Geography, University of California, Santa Barbara, United States \\ c Goddard Space Flight Center, NASA, Greenbelt, MD, United States
}

\section{A R T I C L E I N F O}

\section{Article history:}

Received 16 April 2009

Received in revised form 6 August 2010

Accepted 18 August 2010

Available online 14 May 2011

\section{Keywords:}

LVIS

AVIRIS

Lidar

Hyperspectral

Biomass

MESMA

Species

Stress

\begin{abstract}
A B S T R A C T
In this paper, we explored fusion of structural metrics from the Laser Vegetation Imaging Sensor (LVIS) and spectral characteristics from the Airborne Visible Infrared Imaging Spectrometer (AVIRIS) for biomass estimation in the Sierra Nevada. In addition, we combined the two sensors to map species-specific biomass and stress at landscape scale. Multiple endmember spectral mixture analysis (MESMA) was used to classify vegetation from AVIRIS images and obtain sub-pixel fractions of green vegetation, non-photosynthetic vegetation, soil, and shade. LVIS metrics, AVIRIS spectral indices, and MESMA fractions were compared with field measures of biomass using linear and stepwise regressions at stand (1 ha) level. AVIRIS metrics such as water band indices and shade fractions showed strong correlation with LVIS canopy height $\left(r^{2}=0.69\right.$, RMSE $=5.2 \mathrm{~m}$ ) and explained around $60 \%$ variability in biomass. LVIS variables were found to be consistently good predictors of total and species specific biomass $\left(\mathrm{r}^{2}=0.77, \mathrm{RMSE}=70.12 \mathrm{Mg} / \mathrm{ha}\right)$. Prediction by LVIS after species stratification of field data reduced errors by $12 \%\left(r^{2}=0.84\right.$, RMSE $\left.=58.78 \mathrm{Mg} / \mathrm{ha}\right)$ over using LVIS metrics alone. Species-specific biomass maps and associated errors created from fusion were different from those produced without fusion, particularly for hardwoods and pines, although mean biomass differences between the two techniques were not statistically significant. A combined analysis of spatial maps from LVIS and AVIRIS showed increased water and chlorophyll stress in several high biomass stands in the study area. This study provides further evidence that lidar is better suited for biomass estimation, per se, while the best use of hyperspectral data may be to refine biomass predictions through a priori species stratification, while also providing information on canopy state, such as stress. Together, the two sensors have many potential applications in carbon dynamics, ecological and habitat studies.
\end{abstract}

(c) 2011 Elsevier Inc. All rights reserved.

\section{Introduction}

Improved estimates of forest aboveground biomass, hereafter "biomass" from remote sensing are critical for reducing uncertainties in the global carbon cycle (Hese et al., 2005; Rosenqvist et al., 2003) and are an important goal for future satellite missions. Although coarse-scale biomass estimates are well documented in temperate forests, they are mostly in the form of field measurements and averages over administrative units (Houghton, 2005). There is a need for higher resolution and spatially continuous estimates to quantify carbon flux and disturbance at scales at which land use activities occur (Houghton, 2005; Keith et al., 2009). Spatial distribution of carbon stocks in combination with species composition and vegetation stress can improve the understanding of ecosystem processes (Chambers et al., 2007; Ustin et al., 2004), carbon dynamics, and habitat structure (Bergen et al., 2007). The availability of such maps over difficult mountain terrain

\footnotetext{
* Corresponding author.

E-mail addresses: aswatan@umd.edu, aswatantran@gmail.com (A. Swatantran).
}

such as the Sierra Nevada can be particularly valuable for natural resource and wildlife habitat management.

Many studies have demonstrated the efficacy of waveform lidar in accurately measuring three-dimensional vegetation characteristics including biomass for different forest cover and types (Drake et al., 2002a; Lefsky et al., 2002). Lidar metrics are less prone to saturation effects even at high biomass levels (Drake et al., 2002a; Hyde et al., 2007a; Lefsky et al., 2002) unlike most remote sensing indices, which saturate at moderate values (Gao, 1996; Huete et al., 1997). Acquiring wall-to-wall coverage of airborne lidar however, is expensive. A promising alternative is to extrapolate forest structure from lidar samples using continuous remotely sensed data. There is considerable interest in fusing sparse but accurate lidar measurements with optical (Asner et al., 2008; Hudak et al., 2002; Hyde et al., 2007a; Kimes et al., 2006) and radar sensors (Treuhaft et al., 2004) to improve prediction accuracy and spatio-temporal coverage of forest structure.

Imaging spectrometers or hyperspectral sensors provide many attributes complementary to canopy structure from lidar and can be used to discriminate vegetation types based on spectral characteristics (e.g. Clark et al., 2005; Dennison \& Roberts, 2003; Martin et al., 
1998). Studies have suggested that spectral attributes (Bergen et al., 2006; Ustin et al., 2004) and species composition (Anderson et al., 2005; Rosenqvist, et al., 2003) from hyperspectral data could improve biomass estimates in conjunction with lidar. However, it is still unclear as to how biophysical and biochemical attributes from hyperspectral data relate with structural attributes from lidar. There also remains considerable uncertainty on the efficacy of combining lidar with hyperspectral sensors for species-specific biomass mapping. Underlying causes of biomass change such as physiological stress, tree mortality and senescence cannot be detected from lidar alone, as it does not differentiate between healthy and stressed vegetation (Rosenqvist et al., 2003). While the ability of hyperspectral data to map stress is recognized (Asner, 1998; Merton, 1998; Roberts et al., 1997), the combined use of the two sensors for mapping vertical structure and stress remains largely unexplored.

Our goal in this study was to explore fusion of waveform lidar from the Laser Vegetation Imaging Sensor (LVIS) with hyperspectral imagery from the Airborne Visible Infrared Imaging Spectrometer (AVIRIS) for mapping biomass and stress in the diverse montane forests of the Sierra Nevada. In particular, we evaluated whether addition of spectral metrics from AVIRIS improved biomass estimates from LVIS. We also assessed whether species stratification using AVIRIS data prior to lidar estimation of biomass increased accuracy. Lastly, we explored the combined potential of the two sensors for mapping stress in the high biomass forests of the Sierra Nevada.

\section{Background}

Lidar and hyperspectral remote sensing are two potentially complementary technologies capable of providing comprehensive structural and biophysical characteristics of vegetation (Koetz et al., 2007). Lidar instruments record the time taken by laser pulses to reach the earth's surface from an aircraft/satellite and back to calculate distance to target. Discrete return lidar devices provide one or more laser returns that can be used for high resolution mapping of terrain and canopy elevation (Lefsky et al., 2002). Waveform lidar instruments digitize the entire outgoing and return signal to provide waveforms, from which various parameters such as subcanopy topography, canopy height, foliage profiles and vertical heterogeneity may be derived (Blair et al., 1999; Dubayah et al., 2000). Waveform metrics from small and large footprint lidar have been used to predict biomass in tropical (Clark et al., 2004; Drake et al., 2002b) and temperate forests (Anderson et al., 2005; Hyde et al., 2005; Lefsky et al., 2002).

Hyperspectral sensors measure vegetation absorption and scattering characteristics in the visible, near infrared and short wave infrared wavelengths of the electromagnetic spectrum. Spectral indices or band ratios from hyperspectral data provide many attributes useful for ecological studies (Ustin et al., 2004) such as chlorophyll content (Elvidge \& Chen, 1995), canopy water status (Gao, 1996; Serrano et al., 2000), vegetation stress (Merton, 1998) and lignin and cellulose content (Curran et al., 2001; Kokaly \& Clark, 1999). Narrow band and derivativebased indices from hyperspectral data are relatively less affected by background soil reflectance (Elvidge \& Chen, 1995), illumination, saturation (Gao, 1996; Pu et al., 2003; Roberts et al., 2004), and other factors that influence broadband vegetation indices such as the normalized difference vegetation index (NDVI). Measures of liquid water (e.g. equivalent water thickness, EWT) from hyperspectral data are highly sensitive to canopy properties such leaf area index (LAI) (Roberts et al., 2004). Measures of plant dry matter have been related to environmental stress (Asner, 1998) and could improve lidar estimates of biomass in areas with low canopy heights and sparse vegetation cover (Bergen et al., 2006; Treuhaft et al., 2004; Ustin et al., 2004).

Spectral Mixture Analysis (SMA) is a widely used remote sensing technique for obtaining ecologically relevant and meaningful components from an image pixel (Adams et al., 1986; Chambers et al.,
2007). In SMA, two or more reference spectra/endmembers such as green vegetation, soil and shade are modeled as linear combinations to estimate sub-pixel fractions of each component. A limitation of SMA is that it uses only one set of reference endmembers to model all pixels in an image. Multiple endmember spectral mixture analysis (MESMA) (Roberts et al., 1998) allows the number and type of reference endmembers to vary on a per-pixel basis, accounting for spectral variability in the landscape and improving the accuracy of resulting fractions. Because MESMA fractions are calculated using the entire spectrum, they are more robust than traditional vegetation indices and have successfully been used for estimating live fuel moisture (Roberts et al, 2006), LAI (Sonnetag et al., 2007) and green biomass in pastures (Numata et al., 2008). MESMA has also been used to map vegetation (Dennison $\&$ Roberts, 2003) and urban land cover (Franke et al., 2009).

Most studies on lidar and hyperspectral fusion have focused on land cover classification. Asner et al. (2008) used lidar to mask gaps and low canopy heights, improving detection of invasive species from AVIRIS for Hawaiian rainforests. Koetz et al. (2007), classified fuel composition from fused lidar and hyperspectral bands using Support Vector Machines (SVM). Classification accuracies from fusion were higher than from either sensor alone. Mundt et al. (2006) fused coregistered lidar and hyperspectral data to map sagebrush communities and suggested further use of classified vegetation maps in biomass calculations. Few studies have explored the combined potential of the two sensors for biomass estimation. Anderson et al. (2008) used Minimum Noise Fraction (MNF) transformed AVIRIS bands in combination with LVIS and reported an $8-10 \%$ increase in biomass prediction accuracy for northeastern temperate forests. There is a need to test similar approaches over a wider range of forest cover and types, while retaining the physical significance of variables.

\section{Study area and data}

\subsection{Study area}

The study site $\left(37^{\circ} 2^{\prime} 34.47^{\prime \prime} \mathrm{N}, 119^{\circ} 9^{\prime} 33.81^{\prime \prime} \mathrm{W}\right)$ covers an area of around 22,000 ha and lies along the western slopes of the Sierra National Forest (Fig. 1), in California, USA. The region has a Mediterranean climate with elevations ranging from $1000 \mathrm{~m}$ to $2500 \mathrm{~m}$. Forests are dense and complex in structure with average biomass values of around $200 \mathrm{Mg} / \mathrm{ha}$, and as high as $1000 \mathrm{Mg} / \mathrm{ha}$ in Giant Sequoia (Sequoiadendron giganteum) stands. Dominant species include red fir (Abies magnifica), white fir (Abies concolor), ponderosa pine (Pinus ponderosa), and California black oak (Quercus kellogi) (Hunsaker et al., 2002).

\subsection{Data}

\subsubsection{Field data}

Field surveys were conducted in 2000 and 2001 (Hyde et al., 2005). A modified stratified random sampling scheme was used to measure structural parameters over 500 plots in the northern and southern Sierra Nevada. Field plots were laid out to provide a statistically representative measure of structural variability for the eight major Wildlife Habitat Relation (WHR) types: montane hardwood, montane hardwood conifer, red fir, white fir, sierran mixed conifer, pines, wet meadow, and barren (Hyde et al., 2005; Mayer \& Laudenslayer, 1988). Structural variables for live trees such as height, diameter at breast height (DBH), crown form, canopy cover, species, heights of dead snags and snag decay classes were recorded for concentric plots with radii of $15 \mathrm{~m}$ ( $0.07 \mathrm{ha}-$ footprint level) and $56.4 \mathrm{~m}$ (1 ha-stand level) respectively. For 1 ha plots, only large trees with dbh greater than $76 \mathrm{~cm}$ were measured. A detailed description of the methods used for field data acquisition is available in Pierce et al. (2002). The study area in the Sierra National forest had 285 measured 


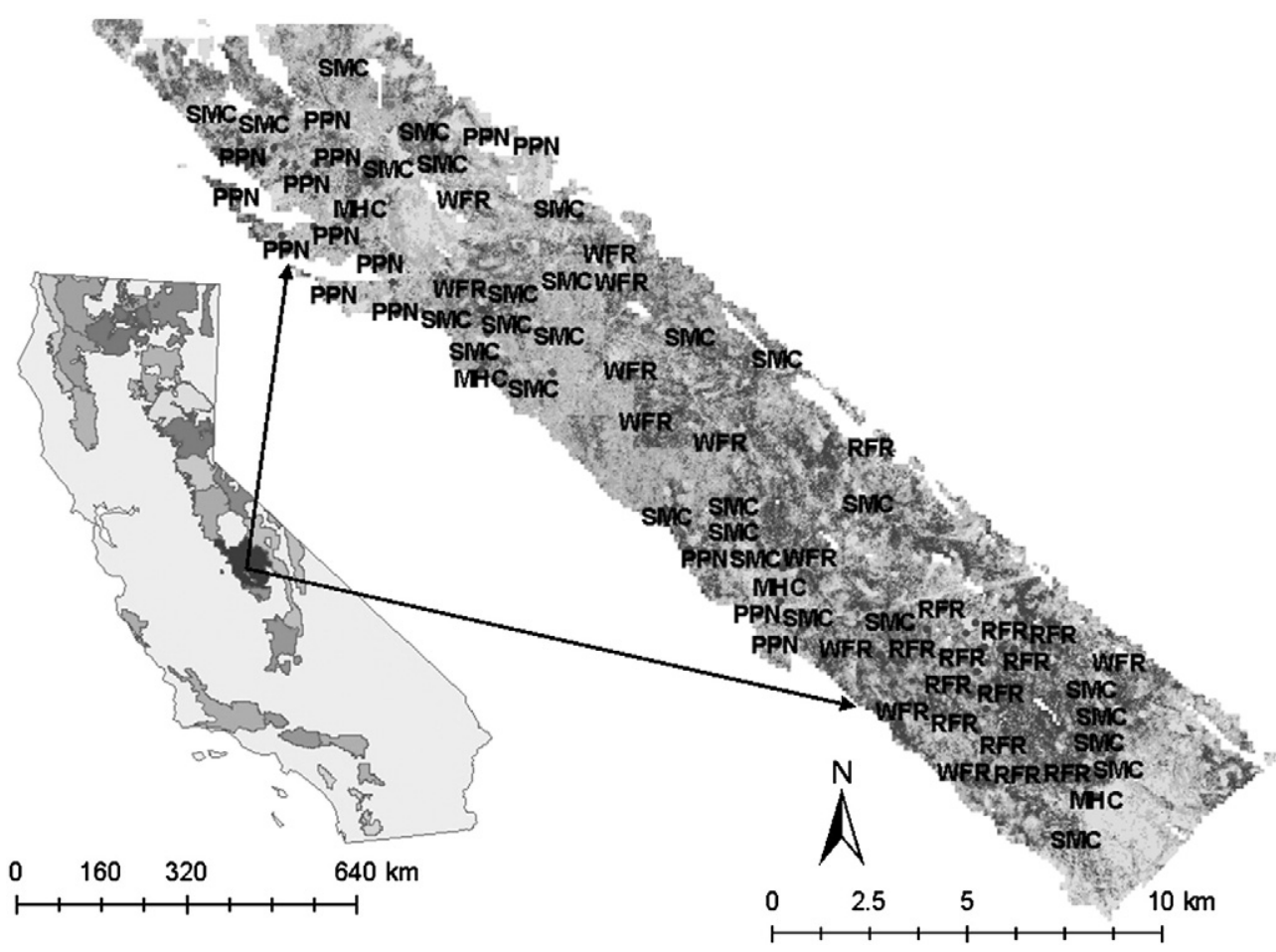

Fig. 1. Study area in the Sierra National Forest showing 1 ha field plots. Plots are classified based on Wildlife Habitat Relation (WHR) type (Table 1 ).

plots out of which 1251 ha plots had collocated lidar, hyperspectral and field measurements and were used for analysis (Table 1 ). The 0.07 ha plots were not used in this study because of increased geolocation errors between reprocessed lidar and field data.

\subsubsection{Lidar data}

The Laser Vegetation Imaging Sensor (LVIS) is a medium footprint, waveform digitizing, scanning laser altimeter, designed, and developed at NASA's Goddard Space Flight Center. LVIS operates at altitudes up to $10 \mathrm{~km}$ with a $7^{\circ}$ field of view and uses laser pulses with a wavelength of $1064 \mathrm{~nm}$ for profiling vertical vegetation structure (Blair et al., 1999). NASA flew LVIS over the Sierra National Forest in summer 1999 at an altitude of $7 \mathrm{~km}$ with trees in leaf-on condition. The lidar shots had a nominal footprint radius of $12.5 \mathrm{~m}$. The data had a swath width of $1 \mathrm{~km}$ and covered an area of $175 \mathrm{~km}^{2}$. The subset used for this study had around 892,444 lidar footprints. Footprints were contiguous along track and overlapping across track (see http://lvis.gsfc.nasa.gov/).

\subsubsection{Hyperspectral data}

The Airborne Visible Infrared Imaging Spectrometer (AVIRIS) designed and developed at the Jet Propulsion Laboratory, measures

Table 1

Distribution of field plots by Wildlife Habitat Relation (WHR) type.

\begin{tabular}{lc}
\hline Species/WHR type & $\begin{array}{l}\text { Number of plots 1 ha } \\
\text { (LVIS, AVIRIS, field) }\end{array}$ \\
\hline WTM (wet meadow) & 8 \\
BAR (barren) & 3 \\
RFR (red fir) & 32 \\
WFR (white fir) & 27 \\
SMC (Sierran mixed conifer) & 37 \\
PPN/JPI (pines) & 18 \\
GSQ (Giant Sequoia) & 1 \\
MHC/MHW & 11 \\
Total & 137 \\
\hline
\end{tabular}

upwelling radiance from the earth's surface in wavelengths between $350 \mathrm{~nm}$ and $2500 \mathrm{~nm}$ in 224 contiguous bands with a bandwidth of $10 \mathrm{~nm}$ (Green et al., 1998). Fine spatial resolution AVIRIS images were acquired over the Sierra Nevada in July 2003. Radiometrically corrected images were processed to retrieve apparent surface reflectance using the MODTRAN based forward inversion approach as described in Green et al. (1993) and Roberts et al. (1997). The images were geometrically corrected using Digital photo Ortho Quads (DOQQ). The AVIRIS data consisted of three overlapping scenes covering a total area of 22,000 ha. Each image had a nominal spatial resolution of $3.3 \mathrm{~m}$ with 224 spectral bands. Bands with a poor signalto-noise ratio from atmospheric interference of water vapor and carbon dioxide were eliminated, resulting in 118 bands for analysis.

\section{Methods}

The data sets used in this study had different geographical projections and were brought into a common frame of reference using the Universal Transverse Mercator Projection (UTM 19N) and NAD 1983 datum. Spatial overlay of AVIRIS and LVIS data showed good geolocation for analysis at the 1 ha level and no further rectification was performed. All hyperspectral processing were done using VIPER tools ENVI-Add on Module $^{\odot}$ (Roberts et al., 2007) and a hyperspectral metrics add on module.

\subsection{Field attributes}

Species-specific allometric equations from the USDA Forest Service (Waddell \& Hiserote, 2003) were used to calculate biomass for all trees with dbh greater than $76 \mathrm{~cm}$ within 1 ha plots. Tree height, species, and dbh measurements from field data were used as inputs for calculating biomass of bole, bark, branches, and foliage separately for each tree. Biomass values for individual trees were then added to obtain aboveground biomass per hectare for large trees within each field plot. Field plots were classified based on WHR type for analysis by species/ vegetation type. Although WHR types consist of species associations, 
most of them have a dominant plant genus/species. The MHC/MHW plots consisted of mixed hardwoods and conifers with broadleaf oaks (Quercus sp.) as the dominant vegetation type. Plots classified as PPN were mostly composed of ponderosa pine (P. ponderosa). SMC plots had mixed conifers including pines (Pinus sp.), firs (Abies sp.), and incense cedar (Libocedrus decurrens) with shade tolerant white fir (A. concolor) becoming increasingly dominant after regeneration from fire (Zald et al., 2008). RFR plots were almost entirely composed of red fir (A. magnifica) trees.

\subsection{LVIS metrics}

An LVIS waveform essentially consists of a signal with amplitudes proportional to energy reflected from intercepted surfaces within canopy and ground. LVIS footprints are geo-located to the global reference ellipsoid WGS 84, using a combination of GPS and Inertial Navigation System (INS) information (Blair et al., 1999; Hofton \& Blair, 2002). Ground elevation is determined by identifying the center of the lowest mode in the waveform greater than mean signal noise (Fig. 2). Canopy elevation is the height at which the signal increases beyond a certain threshold (usually $3 \sigma$ ) at the top of the waveform (Hofton \& Blair, 2002). The difference between canopy elevation and ground elevation gives the canopy height metric or height of $100 \%$ laser energy return (RH100). The 1999 LVIS data were reprocessed using new algorithms for ground detection and an improved horizontal geolocation algorithm (Blair et al., 2006). For each LVIS waveform, quartile heights of laser energy return i.e. height of 25\% (RH25), 50\% (RH50) and 75\% (RH75) energy return were calculated in addition to RH100 (Fig. 2). Canopy cover was calculated from the ground energy return of each waveform normalized by the canopy and background reflectivity ratio (Ni Meister et al., 2001). We used a ratio of 1.6, derived from a previous study (Hyde et al., 2005). LVIS metrics were calculated for lidar shots within 1 ha plots and summarized to obtain minimum, maximum, mean and standard deviation for all metrics.

\subsection{AVIRIS spectral metrics}

Reflectance spectra (e.g. Fig. 3) were extracted from AVIRIS images over field plots to construct a spectral library for the study area. A set of 19 hyperspectral indices (Table 2) was calculated to quantify vegetation attributes from each spectrum and aggregated to obtain mean and standard deviation of values for 1 ha plots. These mainly

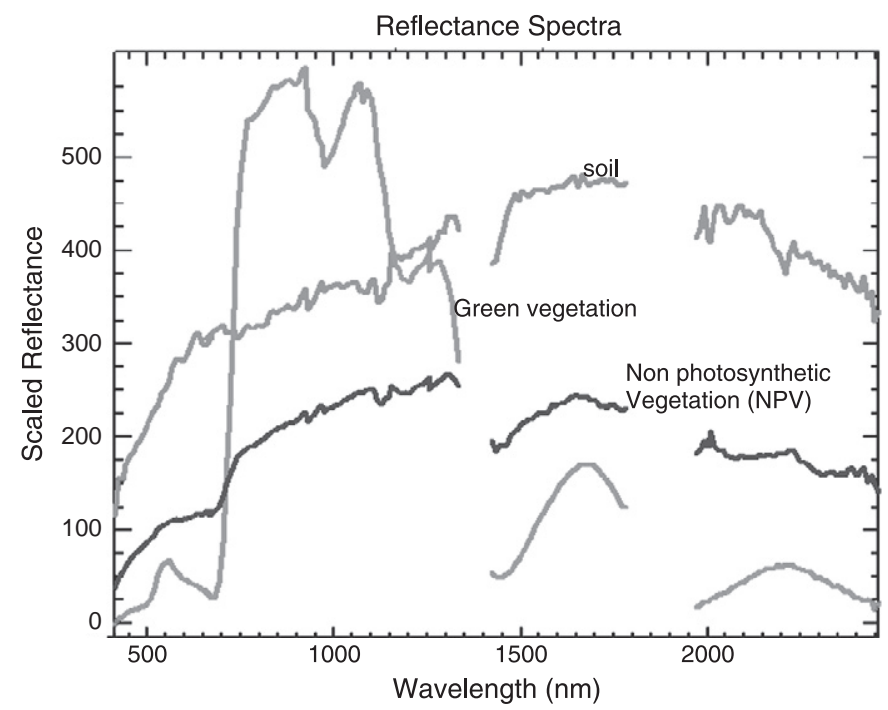

Fig. 3. Examples of reflectance spectra extracted from AVIRIS images over the study area. A set of 19 band ratios describing vegetation characteristics such as chlorophyl content, water content, stress was calculated from the visible, near infrared and short wave infrared wavelengths.

included vegetation indices, derivatives of the chlorophyll red edge, water band ratios, and ligno-cellulose band ratios. Indices based on the green, red, and blue wavelengths were found to be more robust than NDVI in estimating vegetation fractions (Gitelson et al., 2002). We tested the use of green band vegetation indices (VARIGREEN and VIGREEN) in addition to NDVI, Enhanced Vegetation Index (EVI), and Ratio Vegetation Index (RVI) for biomass prediction. Water absorption features in the infrared regions of the spectrum (e.g. $980 \mathrm{~nm} 1450 \mathrm{~nm}$, and $1940 \mathrm{~nm}$ ) are sensitive to canopy biophysical properties (Roberts et al., 2004; Serrano et al., 2000). The Normalized Difference Water Index (NDWI), Equivalent Water Thickness (EWT), and Ratio Water Index (RWI) were used as measures of canopy water content. The red edge or the rapid change in chlorophyll reflectance in the visible and near infrared portion of the spectrum provides a measure of chlorophyll content (Elvidge \& Chen, 1995) and vegetation stress (Merton, 1998). We used the first and second derivatives of the red edge as measures of
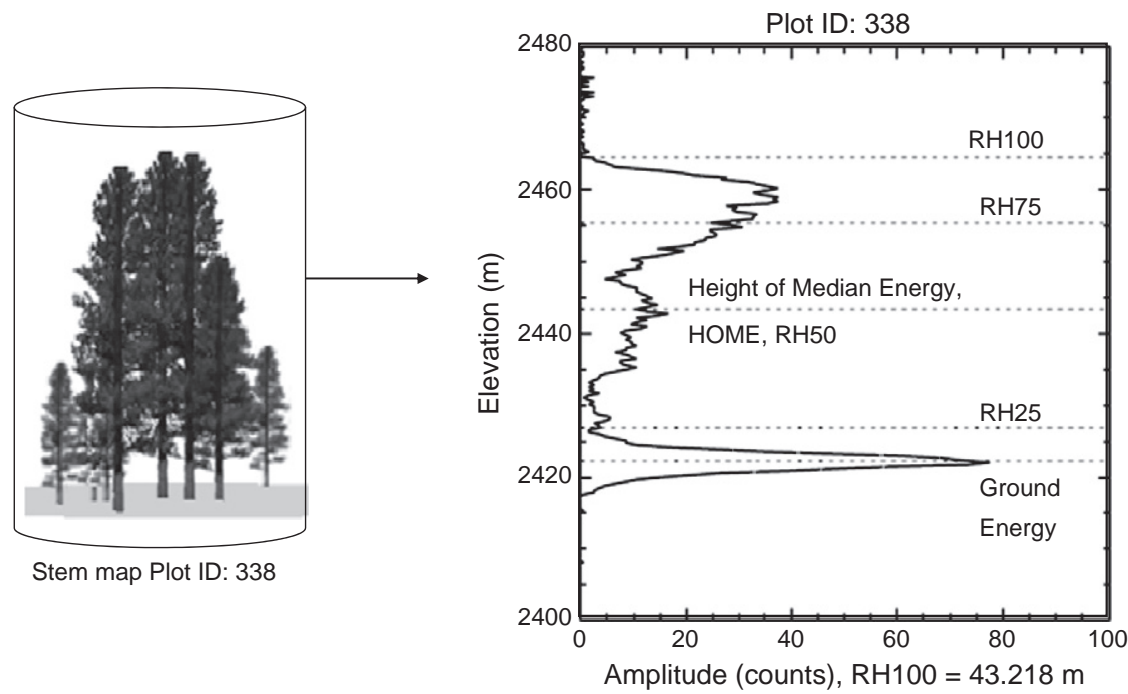

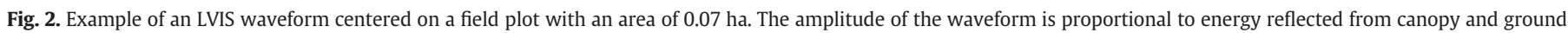
Metrics calculated from the waveform include ground elevation, quartile heights of energy return (RH25, RH50, RH75 and RH100) and canopy cover. 
Table 2

Hyperspectral metrics calculated using AVIRIS data for 1 ha field plots included vegetation indices, red edge derivatives, ligno-cellulose band ratios, and MESMA fractions of green vegetation, soil/NPV, and shade.

\begin{tabular}{|c|c|c|}
\hline Variable & $\begin{array}{l}\text { Hyperspectral metric } \\
\text { (mean, std. deviation) }\end{array}$ & Reference \\
\hline IDL_DGVI & $\begin{array}{l}\text { First derivative of red edge } \\
\text { normalized to } 626-795 \text { baseline }\end{array}$ & Elvidge and Chen (1995) \\
\hline 1DZ_DGVI & $\begin{array}{l}\text { First derivative of red edge } \\
\text { normalized to } 626 \text { baseline }\end{array}$ & Elvidge and Chen (1995) \\
\hline 2DZ_DGVI & $\begin{array}{l}\text { Second derivative of red edge } \\
\text { normalized to } 626 \text { baseline }\end{array}$ & Elvidge and Chen (1995) \\
\hline EVI & Enhanced Vegetation Index & Huete et al. (1997) \\
\hline EWT & Equivalent Water Thickness & Roberts et al. \\
\hline $\begin{array}{l}\text { LC2 BAND } \\
\text { RATIOS }\end{array}$ & $\begin{array}{l}\text { Area, asymmetry, depth, width, } \\
\text { wavelength of SWIR ligno-cellulose } \\
\text { absorption feature } \\
\text { (range } 2045-2218 \mathrm{~nm} \text { ) }\end{array}$ & Kokaly and Clark (1999) \\
\hline NDVI & $\begin{array}{l}\text { Normalized Difference Vegetation } \\
\text { Index NDVI }\end{array}$ & Tucker (1979) \\
\hline NDWI & $\begin{array}{l}\text { Normalized Difference Water } \\
\text { Band Index }\end{array}$ & Gao (1996) \\
\hline RWI & Ratio Water Band Index & Peñuelas et al. (1993) \\
\hline RVI & Ratio Vegetation Index & Jordan (1969) \\
\hline RVSI & Red Edge Vegetation Stress Index & Merton (1998) \\
\hline REDEDGEWAVE & Red Edge Wavelength & Pu et al. (2003) \\
\hline REDEDGEMAG & Magnitude of red edge & Pu et al. (2003) \\
\hline VARIGREEN & $\begin{array}{l}\text { Visible Atmospherically Resistant } \\
\text { Vegetation Index Green }\end{array}$ & Gitelson et al. (2002) \\
\hline VIGREEN & Vegetation Index Green & Gitelson et al. (2002) \\
\hline $\begin{array}{l}\text { SHADE } \\
\text { FRACTION }\end{array}$ & $\begin{array}{l}\text { Fraction of vegetation shade } \\
\text { within each pixel } \\
\text { (calculated using MESMA) }\end{array}$ & $\begin{array}{l}\text { MESMA, Roberts et al. } \\
\text { (1998) }\end{array}$ \\
\hline GV FRACTION & $\begin{array}{l}\text { Fraction of green vegetation } \\
\text { within each pixel } \\
\text { (calculated using MESMA) }\end{array}$ & $\begin{array}{l}\text { MESMA, Roberts et al. } \\
\text { (1998) }\end{array}$ \\
\hline $\begin{array}{l}\text { SOIL + NPV } \\
\text { FRACTION }\end{array}$ & $\begin{array}{l}\text { Fraction of soil + nonphotosynthetic } \\
\text { vegetation within each pixel } \\
\text { (calculated using MESMA) }\end{array}$ & $\begin{array}{l}\text { MESMA, Roberts et al. } \\
\text { (1998) }\end{array}$ \\
\hline
\end{tabular}

chlorophyll content. Wavelength, asymmetry and area of lignin and cellulose absorption features (2045 nm-2218 nm) (Curran et al., 2001; Kokaly \& Clark, 1999) were used to identify non-photosynthetic vegetation; their usefulness in improving biomass estimates in combination with LVIS data was also tested.

\subsection{MESMA fractions from AVIRIS}

The reflectance of an image pixel over a forested area is typically composed of varying combinations of bare soil, shade/shadows, green vegetation (GV) from foliage and non-photosynthetic vegetation (NPV) from dead bark, leaf litter or senescent vegetation (Chambers et al., 2007; Roberts et al., 2004). Multiple endmember spectral mixture analysis (MESMA) involves creation of regionally specific libraries by using reference spectra from an image, field, or modeled spectra. Each spectrum in the reference spectral library is modeled as a combination of another spectrum and shade (Dennison et al., 2004).

Three fit metrics are used to identify representative spectra or endmembers for each class: Count Based endmember (COB) (Franke et al., 2009; Roberts et al., 2003), Endmember Average Root mean square error (EAR) and Minimum Average Spectral Angle (MASA). COB values are used to select endmembers that model spectra within the same class (In COB) better than those in other classes (Out COB). EAR values are used to select spectra with lowest root mean square error in modeling other spectra of the same class (Dennison \& Roberts, 2003). Spectra with low average spectral angle values (MASA) are selected as reference endmembers. A detailed description of MESMA and fit metrics can be found in Dennison et al. (2004).

A library was created for the Sierra Nevada from AVIRIS images by extracting reference spectra for grass, shrubs, trees, soil, and NPV using field data and image interpretation. Each spectrum in the library was modeled as a combination of another spectrum and shade. We selected endmembers with high In $\mathrm{COB}$ values followed by those with low MASA and EAR values (Table 3). Several models with varying combinations of endmembers were tested using SMA/MESMA. For this study, we used 10 three-endmember (soil, green vegetation, and shade) models for unmixing the AVIRIS images. Soil and NPV endmembers were combined into one class. The resulting image consisted of fractional abundances of green vegetation, soil/NPV, and shade for each pixel at $3.3 \mathrm{~m}$ nominal spatial resolution (Fig. 4). MESMA fractions were then summarized to calculate mean and standard deviation of values for 1 ha field plots.

\subsection{Land-cover classification from AVIRIS}

We also used MESMA to classify land cover and dominant vegetation type from AVIRIS images. A spectral library was constructed from the AVIRIS images using field knowledge, coarse vegetation type maps (USDA Forest Service CALVEG data, 2007), lidar height maps, and image interpretation. We isolated patches of vegetation with dense canopy cover and extracted relatively pure spectra for oaks (Quercus sp.), white fir (A. concolor), red fir (A. magnifica), mixed firs (Abies sp.), and pines (Pinus sp.). Field knowledge was used to avoid plots with abundant ground cover of chaparral (Ceonothus sp. and Arctostaphylos sp.) and reduce mixing with canopy dominant spectra. Spectral metrics from AVIRIS such as NDVI, NDWI, EWT, and lignocellulose band ratios were also useful for separating non-photosynthetic vegetation, bare soil, and spectra for dominant vegetation types.

Each spectrum in the library of 183 spectra was unmixed with another spectrum and shade resulting in 182 unique two endmember models for each spectrum. Fit metrics EAR, MASA, and COB (see Section 4.4) were used to select suitable reference endmembers for land cover classification. We selected 47 spectra from several classes including pines, hardwoods, grass, soil, NPV, and chaparral. All AVIRIS images were unmixed using 47 two-endmember MESMA models to map land cover/dominant vegetation type (Fig. 5a). Outputs included dominant land cover type in each pixel and the corresponding fractional abundance. Pixels mapped as soil, rock, NPV, chaparral, and grass in the AVIRIS vegetation map were excluded. A vector grid of 1 ha polygons was placed over the species map and class statistics were calculated for pixels with pines, firs (red and white), and hardwoods within each polygon. The dominant class in each polygon was recorded to create an aggregated 1 ha species map (Fig. 5b).

\section{Analysis}

\subsection{Stand level}

The final data for stand level (1 ha) analysis included fieldmeasured biomass, LVIS metrics, spectral indices, and MESMA fractions from AVIRIS. Wet Meadow (WTM) and barren (BAR) plots were excluded and 125 other plots with collocated LVIS, AVIRIS, and field data were used. We tested several linear and multiple stepwise

\section{Table 3}

Reference endmembers used in 10 3-endmember MESMA models for unmixing AVIRIS images. Soil and non-photosynthetic vegetation (NPV) spectra were grouped into one class. Fit metrics-EAR, MASA, and COB values were used to select the best representative spectra to un-mix the entire image.

\begin{tabular}{llllllll}
\hline Endmember & Class & Brightness & EAR & MASA & In COB & Out Cob & CoBI \\
\hline Rock/soil & Soil/NPV & 421.53 & 0.13 & 0.66 & 10 & 0 & 0 \\
Soil & Soil/NPV & 345.05 & 0.04 & 0.095 & 0 & 0 & 0 \\
NPV & Soil/NPV & 254.47 & 0.04 & 0.13 & 0 & 0 & 0 \\
NPV & Soil/NPV & 260.65 & 0.04 & 0.133 & 6 & 2 & 0.08 \\
NPV & Soil/NPV & 203.46 & 0.08 & 0.24 & 17 & 1 & 0.46 \\
Green vegetation & GV & 188.92 & 0.09 & 0.39 & 0 & 0 & 0 \\
Green vegetation & GV & 210.73 & 0.09 & 0.41 & 0 & 0 & 0 \\
\hline
\end{tabular}




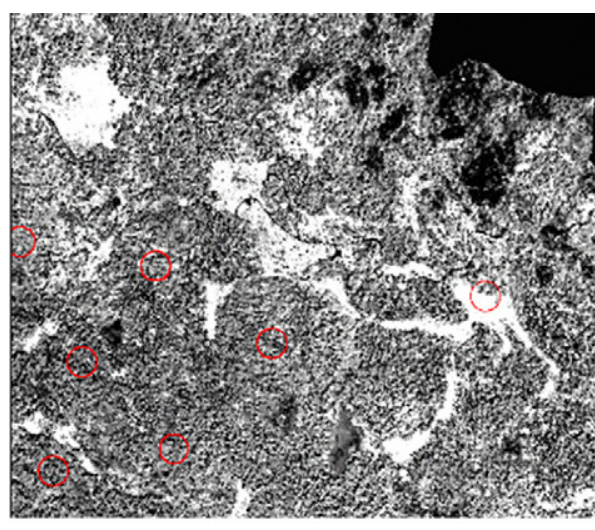

Green Vegetation (GV) fraction

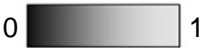

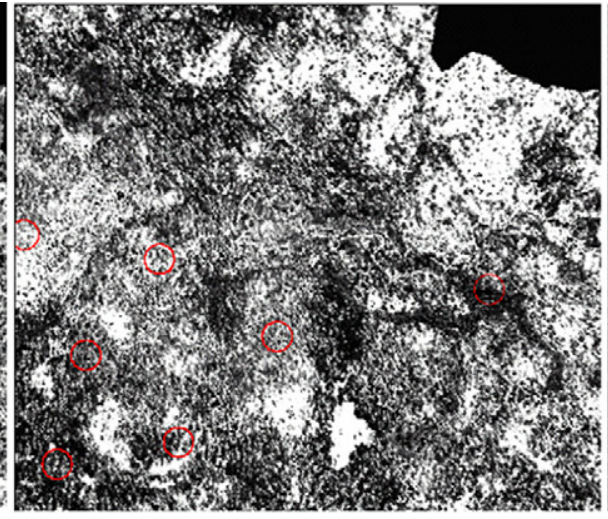

Soil/NPV fraction

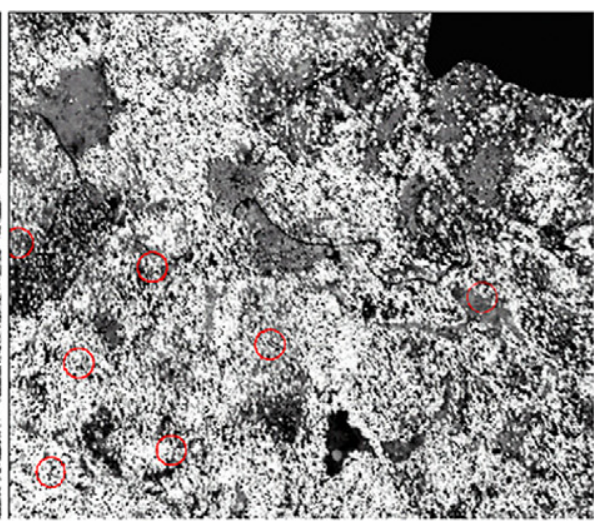

Shade fraction

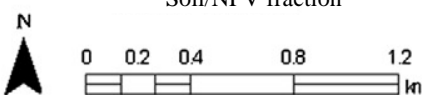

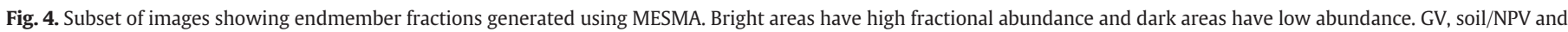
shade fractions were summarized to calculate mean and std. deviation of values for 1 ha plots.

regression models to predict biomass before and after species stratification. Models for predicting total and species-specific biomass were tested using AVIRIS metrics alone, LVIS variables alone and a combination of AVIRIS and LVIS metrics. Three parameters were used to select the best models; high co-efficient of determination values $\left(r^{2}\right)$, low Root Mean Squared Error (RMSE), and $p$ value $<0.05$ for $r-$ squared as well as predictor variables. The Akaike information criteria (AIC) were used to select suitable predictor variables for all models. We also tested variable selection using Bayesian model averaging
(BMA). Confidence intervals for coefficients of determination were calculated to compare the statistical significance of different models.

\subsection{Landscape level}

Equations from stand level analysis were used to generate landscape maps to study variations between biomass from LVIS alone and speciesspecific biomass from fusion. The vegetation map at 1 ha had four classes: hardwoods, pines, white fir/mixed conifers, red fir. White fir ( $A$.

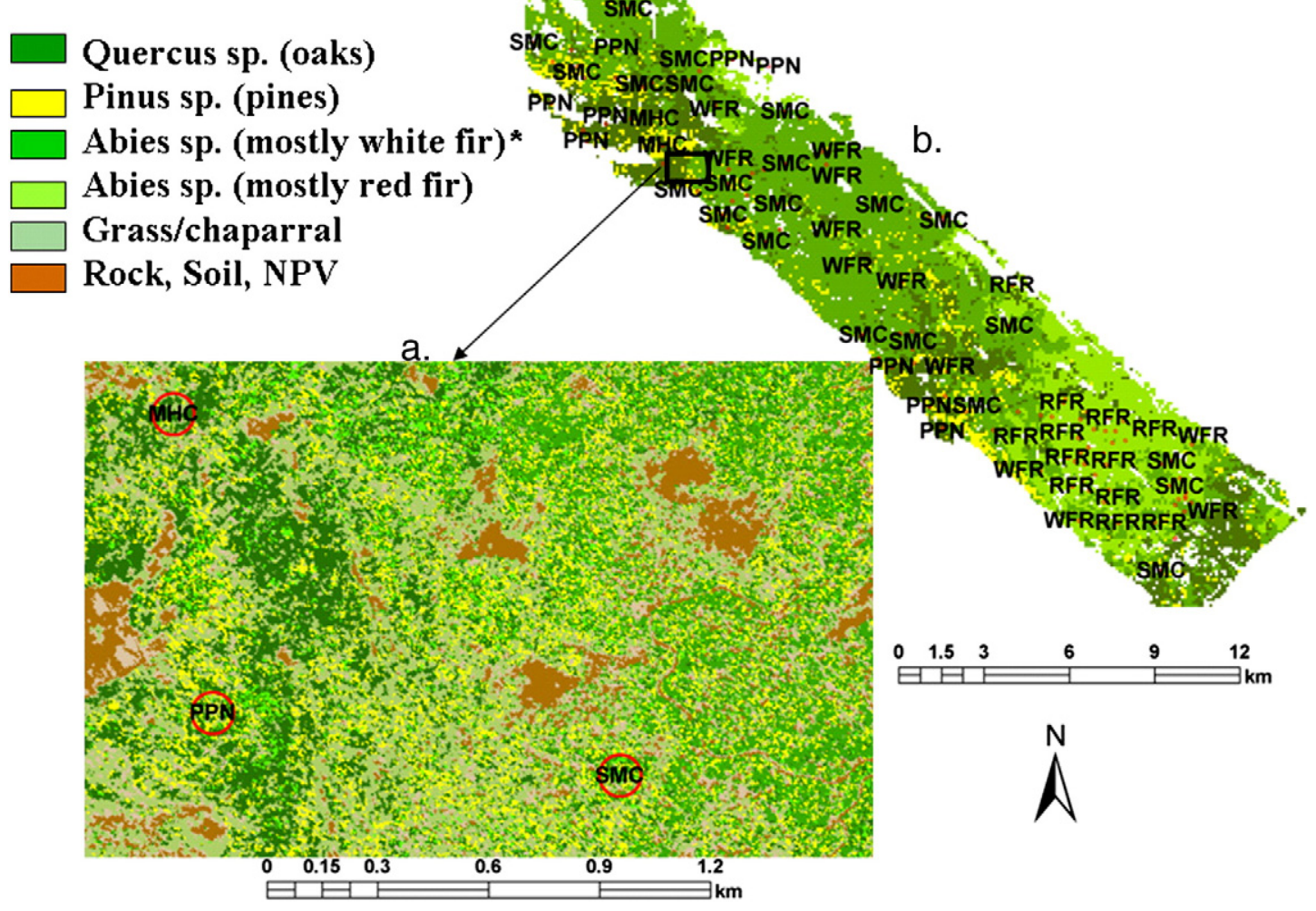

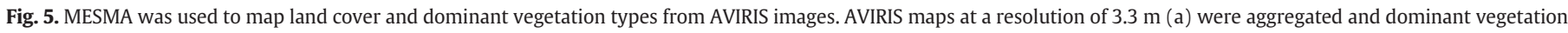

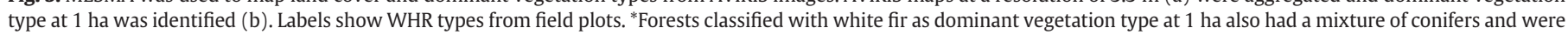
grouped as the SMC type for biomass estimation. 
concolor) and red fir (A. magnifica), were grouped into one class at lower elevations ( $<2000 \mathrm{~m}$ ) because of mixing. At the hectare level, mixing of species/genera within each class was unavoidable, but our vegetation classes closely matched the WHR type classification from the USDA Forest Service map at a coarser resolution. For example, polygons grouped as hardwoods were similar in distribution to the MHC/MHW type; pines were similar to the PPN type. Polygons with white fir as the dominant species also had a mix of pines, red fir and some hardwoods. These polygons were grouped under the firs/mixed conifer type. Biomass was calculated for each dominant vegetation type using equations derived from lidar and field data (Table 5).

Spatial patterns of AVIRIS vegetation indices, water band indices and red edge derivatives were analyzed in combination with lidar heights, canopy cover, and biomass predicted from fusion. We used the NDWI as an indicator of water content (Gao, 1996; Serrano et al., 2000; Maki et al., 2004) and the normalized first derivative of red edge, D1GVI as an indicator of chlorophyll content (Merton, 1998; Smith, 2004). The species biomass map from fusion was combined with NDWI and D1GVI maps to detect 1 ha stands with biomass greater than $200 \mathrm{Mg} / \mathrm{ha}$, canopy cover greater than 40\%, NDWI less than 0.05 and D1GVI less than 0.1 . Stands with biomass greater than $200 \mathrm{Mg} / \mathrm{ha}$, canopy cover greater than $40 \%$, NDWI greater than 0.05 and D1GVI greater than 0.1 were identified as areas with relatively low stress. To rule out effects of soil reflectance on water band indices (Gao, 1996) we further analyzed NPV fractions within canopies alone by masking other land cover types.

\section{Results}

\subsection{Stand level}

AVIRIS variables explained around $60 \%$ of the variability in biomass $\left(r^{2}=0.60, R M S E=92.13 \mathrm{Mg} / \mathrm{ha}\right)$ with water band indices being the most important variables (Fig. 6a). LVIS height metrics were found to be consistently better predictors of total and species specific biomass. The best model for stand level prediction had an $r^{2}=0.77$, $\mathrm{RMSE}=70.12 \mathrm{Mg} / \mathrm{ha}$, with $\mathrm{RH} 75$ being the single best predictor (Fig. 6b). AVIRIS metrics showed marginal improvement in biomass prediction (but not statistically significant) when combined with LVIS metrics for 1 ha plots $\left(r^{2}=0.80, R M S E=64.18 \mathrm{Mg} / \mathrm{ha}\right.$ ) (Table 4, Fig. 6c). AVIRIS variables including water band ratios (RWI, NDWI, EWT) and shade fractions from MESMA showed strong correlation with LVIS heights $\left(r^{2}=0.69\right.$, RMSE $\left.=5.2 \mathrm{~m}\right)$. Mean and standard deviation of shade fractions alone explained more than $50 \%$ variability in all LVIS metrics (for example, $\mathrm{r}^{2}=0.54$, RMSE $=6.25 \mathrm{~m}$ for $\mathrm{RH} 100$ ).

Species-specific biomass relationships were analyzed for 125 plots (excluding barren and meadow plots). Classification of field plots by vegetation type/species before biomass estimation from LVIS improved prediction accuracy $\left(\mathrm{r}^{2}=0.84, \mathrm{RMSE}=58.78 \mathrm{Mg} / \mathrm{ha}\right)$ (Fig. 6d). The maximum increase in predicted values was observed for MHC/MHW plots with hardwoods as dominant vegetation $\left(r^{2}=0.94, R M S E=12.7 \mathrm{Mg} / \mathrm{ha}\right)$. For other dominant vegetation types, there was little change or even a slight increase in RMSE with species stratification (Table 5). RH75 was again the single best predictor of biomass for almost all vegetation types. AVIRIS metrics showed strong correlation with biomass for pines and hardwoods $\left(\mathrm{r}^{2}\right.$ greater than 0.7). Relationship between AVIRIS metrics and field biomass decreased considerably $\left(r^{2}\right.$ less than 0.45$)$ in high biomass plots of red fir (A. magnifica) and mixed conifers.

\subsubsection{Statistical significance of models}

Confidence intervals for coefficients of determination were calculated for all the models used to predict biomass (Fig. 7). Prediction using lidar variables alone showed a statistically significant improvement over the model using AVIRIS variables alone. Addition

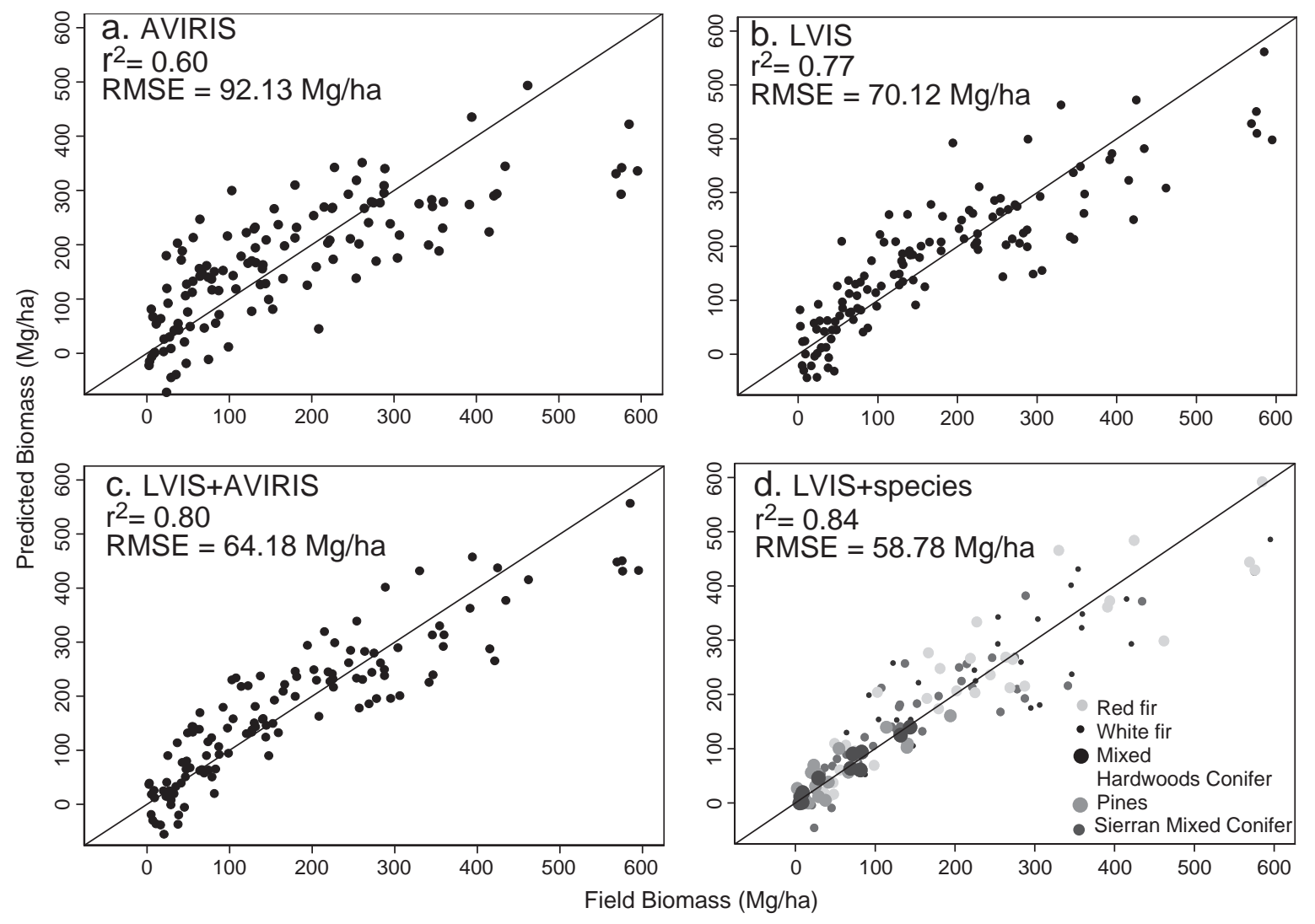

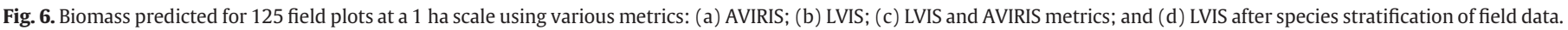


Table 4

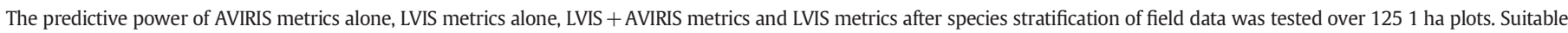
predictor variables were selected using AIC criteria. The best model was obtained by predicting biomass with LVIS variables after stratifying field plots into WHR/species type.

\begin{tabular}{|c|c|c|}
\hline \multirow[t]{2}{*}{ Regression model } & \multicolumn{2}{|c|}{ Predicted biomass56.4 m ( 1 ha) $n=125$} \\
\hline & $\mathrm{R}^{2}$ (95\% C.I.) & RMSE (Mg/ha) \\
\hline $\begin{array}{l}\text { Field biomass } \sim \text { AVIRIS } \\
\quad(\text { Biomass }=8865 \text { sdNDWI }-1624.13 \text { sdNDVI }-5421.92 \text { sdEWT }+3658.35 \text { mean NDWI } \\
-1218.99 \text { mean EWT }-28.90 \text { mean RVI }+20166.10 \text { sdRVSI }-125305.76 \text { mean Rededgemag })\end{array}$ & $\begin{array}{l}0.60 \\
(0.49-0.69)\end{array}$ & 92.13 \\
\hline $\begin{array}{l}\text { Field biomass } \sim \text { LVIS metrics } \\
\quad(\text { Biomass }=60.58 \text { mean RH75 }-698.24 \text { mean CCover }-27.84 \text { mean RH100 + 149.18) }\end{array}$ & $\begin{array}{l}0.77 \\
(0.69-0.83)\end{array}$ & 70.12 \\
\hline $\begin{array}{l}\text { Field biomass } ~ \text { LVIS }+ \text { AVIRIS metrics } \\
\quad(\text { Biomass }=55.83 \text { mean RH75 }-24.76 \text { mean RH100 }-776.32 \text { mean CCover } \\
-526.10 \text { mean1DZ_DGVI }+820.65 \text { mean NDWI }-5299.80 \text { sdlc2dpth }+339.99)\end{array}$ & $\begin{array}{l}0.80 \\
(0.74-0.86)\end{array}$ & 64.18 \\
\hline $\begin{array}{l}\text { Species specific biomass from field LVIS } \\
\text { (equations in Table 5) }\end{array}$ & $\begin{array}{l}0.84 \\
(0.79-0.88)\end{array}$ & 58.78 \\
\hline
\end{tabular}

of AVIRIS variables to LVIS did not show a significant improvement over LVIS metrics alone. Species stratification prior to lidar estimation of biomass reduced prediction errors from LVIS alone by $12 \%$, but the reduction was again not statistically significant. However, confidence intervals for the model using species stratification were narrower than the other models.

\subsection{Landscape level}

\subsubsection{Classified land cover map}

An error matrix was generated to assess the accuracy of the AVIRIS image classification. 183 reference spectra were modeled using 47 spectra in the selected MESMA model. Classification results showed an overall accuracy of $87.7 \%$ for level 1 (genera/species) with a kappa value of 0.86 (Table 6 ). Errors were higher because of mixing between white fir (A. concolor) and red fir (A. magnifica) spectra. Level 2 classification (plant functional type/genera) had a higher accuracy of 93\%. It was noted that around 14 spectra in the original library were left un-modeled. Visual comparisons showed that the dominant vegetation types in the AVIRIS maps were similar to WHR types in the USDA Forest Service map. At the hectare level, we generated an error matrix using WHR types from field polygons as reference (Table 7). Overall accuracy for this classification was $69.5 \%$. Accuracy could be lower $(45 \%)$ in areas with greater mixing between pines, firs, and hardwoods. Accuracy was also lower because the reference maps were classified as discrete polygons and were at a coarser scale than the AVIRIS classified map.

\subsubsection{Biomass}

Biomass maps predicted from LVIS before and after species stratification showed large differences in spatial variability, mainly in forests with hardwoods and pines as dominant vegetation type (Fig. 8). Histograms of biomass distribution before and after species stratification showed increases in predicted values for both hardwoods and pines in low biomass ranges ( $<50 \mathrm{Mg} / \mathrm{ha})$ and decreases in high ranges ( $>200 \mathrm{Mg} / \mathrm{ha}$ ) (Fig. 9). High biomass firs and mixed conifer stands showed little variation in predicted values before and after species stratification. Histograms of biomass for hardwoods and pines derived using classified AVIRIS maps and from USDA Forest Service vegetation maps showed similar trends in low and high biomass ranges.

\subsubsection{Stressed biomass}

Combined analysis of AVIRIS and LVIS metrics revealed spatial patterns that could not be detected from either sensor alone (Fig. 10). For most of the study area, water band indices, red edge derivatives and vegetation indices had very low values over barren land, exposed rock surfaces, and higher values over dense forests and wet meadows. However, we found low values for water band indices and vegetation indices in some high biomass ( $>200 \mathrm{Mg} / \mathrm{ha}$ ) forests, particularly in red fir

Table 5

Biomass was predicted using a single lidar equation before species stratification and a different equation for each species after stratification of field plots by WHR type.

\begin{tabular}{|c|c|c|c|c|}
\hline \multirow[t]{2}{*}{ WHR type } & \multicolumn{2}{|c|}{$\begin{array}{l}\text { Biomass predicted using single lidar } \\
\text { equation } \\
\text { Total biomass (actual vs. predicted) } \\
\mathrm{r}^{2}=0.77, \mathrm{RMSE}=70.12 \mathrm{Mg} / \mathrm{ha}\end{array}$} & \multicolumn{2}{|l|}{$\begin{array}{l}\text { Biomass predicted using a different equation for each species. } \\
\text { Species specific biomass (actual vs. predicted) } \\
\mathrm{r}^{2}=0.84, \mathrm{RMSE}=58.78 \mathrm{Mg} / \mathrm{ha}\end{array}$} \\
\hline & $r^{2}(95 \%$ C.I. $)$ & RMSE (Mg/ha) & $r^{2}(95 \%$ C.I. $)$ & RMSE (Mg/ha) \\
\hline $\begin{array}{l}\text { Montane Hardwood Conifer } \\
\qquad(\mathrm{MHC}) \mathrm{n}=10\end{array}$ & $\begin{array}{l}0.82 \\
(0.41-0.96)\end{array}$ & 22.6 & $\begin{array}{l}0.94 \\
(0.77-0.99) \\
\text { Biomass }=6.03 \text { mean } \mathrm{RH} 75-29.60\end{array}$ & 12.7 \\
\hline $\begin{array}{l}\text { Sierran Mixed Conifer } \\
\qquad(\mathrm{SMC}) \mathrm{n}=37\end{array}$ & $\begin{array}{l}0.77 \\
(0.60-0.88)\end{array}$ & 60.35 & $\begin{array}{l}0.78 \\
(0.61-0.89) \\
\text { Biomass }=49.69 \text { mean } \mathrm{RH} 75-20.98 \text { mean } \mathrm{RH} 100 \\
-553.06 \text { mean CCover }+77.21\end{array}$ & 59.73 \\
\hline Red Fir (RFR) $n=32$ & $\begin{array}{l}0.82 \\
(0.67-0.91)\end{array}$ & 71.02 & $\begin{array}{l}0.83 \\
(0.68-0.91) \\
\text { Biomass }=81.57 \text { mean } \\
\text { RH75 }-40.7512 \text { mean } \text { RH100 }-1009.77 \text { meanCCover }+255.02\end{array}$ & 69.82 \\
\hline White Fir (WFR) $n=27$ & $\begin{array}{l}0.70 \\
(0.45-0.85)\end{array}$ & 75.59 & $\begin{array}{l}0.70 \\
(0.45-0.85) \\
\text { Biomass }=70 \text { mean } \mathrm{RH} 75-31.55 \text { mean } \mathrm{RH} 100 \\
-669.16 \text { mean CCover }+86.42\end{array}$ & 74.63 \\
\hline Pines (PPN) $n=18$ & $\begin{array}{l}0.75 \\
(0.46-0.90)\end{array}$ & 28.22 & $\begin{array}{l}0.75 \\
(0.43-0.90) \\
\text { Biomass }=5.95 \text { mean } \mathrm{RH} 75-45.84\end{array}$ & 28.7 \\
\hline
\end{tabular}




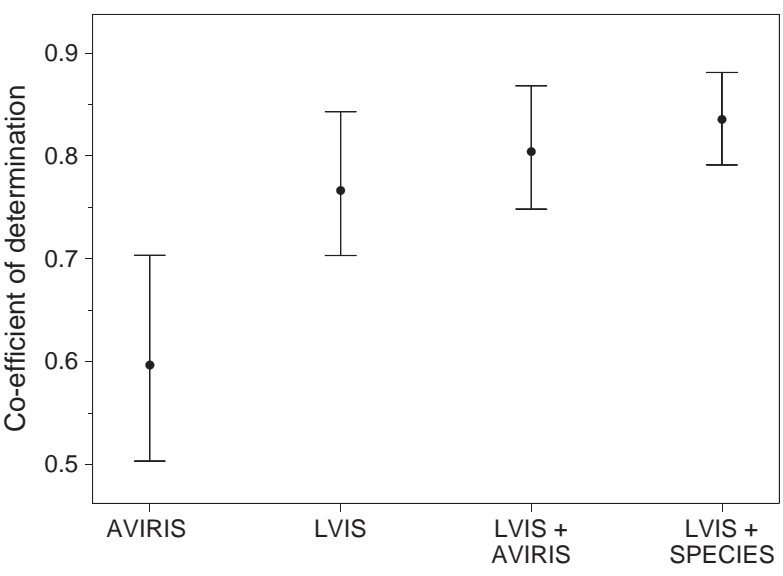

Fig. 7. Coefficients of determination for predicted biomass with $95 \%$ confidence intervals. Narrower confidence intervals for LVIS + species stratification suggest a small improvement, but overlap of intervals shows that it is not statistically significant.

stands around the Teakettle Experimental Forest (Smith et al., 2005) and some mixed conifer stands (Fig. 11). NPV fractions were also high in the areas where we detected water and chlorophyll stress (Fig. 12).

\section{Discussion}

Our first objective was to test the efficacy of combining hyperspectral metrics with lidar variables for biomass prediction. AVIRIS band indices and MESMA fractions added little explanatory value to LVIS, even though they explained around $60 \%$ of the variability in biomass at the stand level. This was because of strong correlations between LVIS and AVIRIS metrics, particularly water band indices and shade fractions. Similar relationships between field measured canopy height and shade fractions were reported by Numata et al. (2008). Shade fractions are related to canopy structure, so this correlation is not unexpected. Roberts et al. (2004) showed that liquid water is highly sensitive to LAI, which may explain the observed correlation between water band indices and structural metrics from LVIS that respond most strongly to photosynthetic leaf material. Our results also showed that narrow band AVIRIS metrics such as red edge derivatives were more sensitive to biomass than NDVI, similar to Elvidge and Chen (1995), Roberts et al. (1997), and Roberts et al. (2004). However, these metrics suffered saturation effects over the high biomass range of this study area.

Although AVIRIS metrics did not add much predictive power in our moderately high biomass test area, shade fractions and water band indices may be useful in areas with lower biomass and little or no lidar coverage. Approximately $40 \%$ of the world's forests fall in the low canopy height, low biomass category (Bergen et al., 2006), where lidar
Table 7

Error matrix for assessing classification accuracy at hectare level. WHR types from field polygons were used as ground reference. Overall accuracy $=69.5 \%$.

\begin{tabular}{llllll}
\hline \multirow{2}{*}{$\begin{array}{l}\text { WHR type/field } \\
\text { polygons }\end{array}$} & \multicolumn{5}{l}{ Dominant vegetation type AVIRIS 1 ha map } \\
\cline { 2 - 6 } & Hardwoods & Pines & $\begin{array}{l}\text { White fir/mixed } \\
\text { conifers }\end{array}$ & $\begin{array}{l}\text { Firs/mostly } \\
\text { red }\end{array}$ & $\begin{array}{l}\text { Total } \\
\text { classified }\end{array}$ \\
\hline MHC/MHW & 6 & 7 & 5 & 0 & 18 \\
PPN & 1 & 2 & 5 & 0 & 8 \\
SMC & 0 & 4 & 35 & 0 & 39 \\
RFR & 0 & 0 & 10 & 30 & 40 \\
Total ground truth & 7 & 13 & 55 & 30 & 105 \\
Overall accuracy & $69.5 \%$ & & & & \\
\hline
\end{tabular}

performance is largely untested. The potential of hyperspectral and other optical imagery in extrapolating forest structure from lidar samples in such areas requires further investigation.

Previous studies combining lidar with multispectral (Hyde et al., 2007a), radar (Hyde et al., 2007b) and hyperspectral sensors (Anderson et al., 2008) have shown that lidar was more useful than other sensors for biomass prediction. Our results further support this. Drake et al. (2002a) and Anderson et al. (2008) have shown the predictive power of the RH50 metric and suggested the use of canopy cover to improve biomass estimates from LVIS. We additionally included RH75 and canopy cover to the variables used by Hyde et al. (2005) for the Sierra Nevada. Although both RH50 and RH75 were strongly correlated with biomass, RH75 was consistently selected as the best predictor variable in all regression models. One probable reason could be the species composition and vertical foliage distribution in this study area. Further analysis of lidar waveforms, foliar profiles, and stem densities within lidar footprints is required to understand the physical significance of RH75 in biomass estimation for the Sierra Nevada.

The issue of the efficacy of fusing lidar and hyperspectral data for species level biomass estimation remains open. Similar to Anderson et al. (2008), our results show that a combination of LVIS and AVIRIS metrics improves biomass estimates marginally than using either sensor alone. Anderson et al. (2008) found that AVIRIS metrics explained most of the variability in species fractions of biomass for northeastern temperate forests. Our results show that LVIS metrics were better predictors of species level biomass (Table 5) while AVIRIS metrics were mostly redundant when combined with LVIS. One reason could be the difference in tree species in the Sierra Nevada as compared to Bartlett. Most of the species in Bartlett are broadleaf deciduous, while in the Sierra Nevada they are conifer dominants. Another reason could be that the predictive power of AVIRIS is higher when lidar relationships with biomass are weaker as observed in the Bartlett Experimental Forest. A study by Roth (2009) showed similar results for the Smithsonian Environmental Research Center (SERC) study site. Lidar metrics in the Sierra Nevada study area were strongly correlated with biomass, so addition of AVIRIS probably did not show much improvement.

Table 6

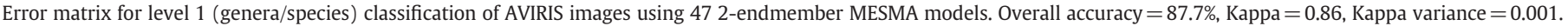

\begin{tabular}{|c|c|c|c|c|c|c|c|c|c|c|}
\hline Matrix & Firs/mixed & Granite & Grass & Chaparral & NPV & $\begin{array}{l}\text { Pines } \\
\text { (Pinus sp.) }\end{array}$ & $\begin{array}{l}\text { Hardwoods } \\
\text { (Quercus sp.) }\end{array}$ & $\begin{array}{l}\text { Red fir } \\
\text { (Abies magnifica) }\end{array}$ & Soil & $\begin{array}{l}\text { White fir } \\
\text { (Abies concolor) }\end{array}$ \\
\hline Firs/mixed & 2 & 0 & 0 & 0 & 0 & 0 & 0 & 0 & 0 & 1 \\
\hline Granite & 0 & 20 & 0 & 0 & 0 & 0 & 0 & 0 & 3 & 0 \\
\hline Grass & 0 & 0 & 5 & 0 & 0 & 0 & 0 & 0 & 0 & 0 \\
\hline Chaparral & 0 & 0 & 0 & 24 & 0 & 0 & 0 & 0 & 0 & 0 \\
\hline NPV & 0 & 0 & 0 & 0 & 17 & 0 & 0 & 0 & 0 & 0 \\
\hline Pines (Pinus sp.) & 1 & 0 & 0 & 0 & 0 & 6 & 0 & 1 & 0 & 0 \\
\hline Hardwoods (Quercus sp.) & 0 & 0 & 0 & 1 & 0 & 1 & 3 & 0 & 0 & 0 \\
\hline Red fir (Abies magnifica) & 4 & 0 & 0 & 0 & 0 & 0 & 0 & 8 & 0 & 0 \\
\hline Soil & 0 & 0 & 0 & 0 & 1 & 0 & 0 & 0 & 15 & 0 \\
\hline White fir (Abies concolor) & 1 & 0 & 0 & 0 & 0 & 0 & 0 & 1 & 0 & 7 \\
\hline
\end{tabular}



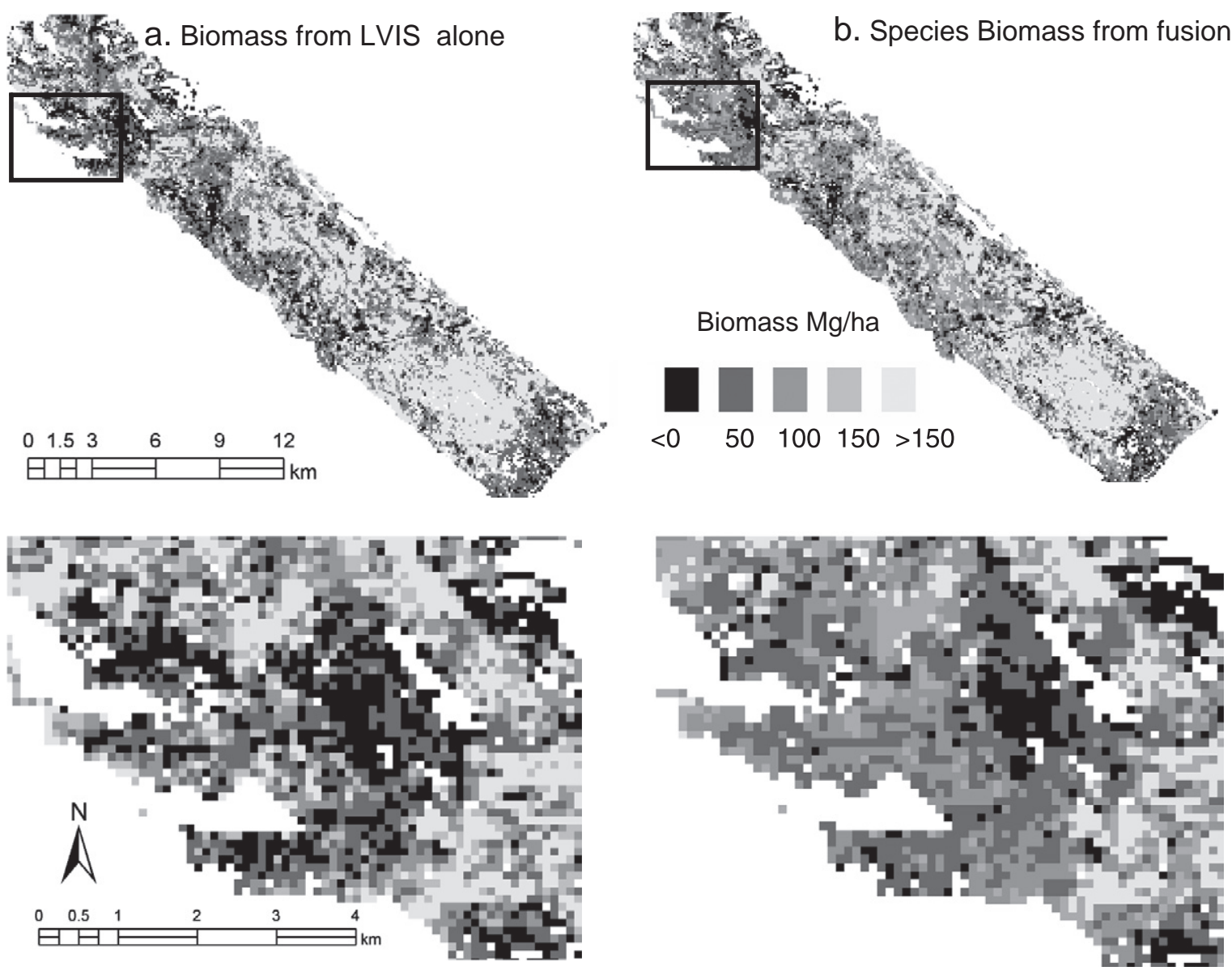

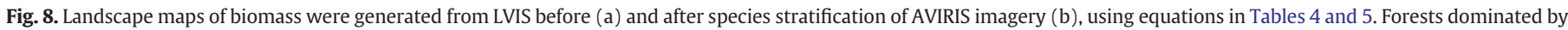
pine and hardwood species (e.g. black rectangle) show more spatial variations in predicted biomass.

The overlap of confidence intervals of the coefficients of determination before and after species stratification suggests that overall predictive power for biomass was not significantly higher at the species level for our study area. Part of the reason for this could be the relatively small sample size used in this study. The dominance of high biomass mixed conifers and low abundance of deciduous species in the study area could have also affected the results. Yet another factor could be the relatively coarse spatial scale of 1 ha used in our study, one that is large enough to encompass various species and canopy configurations. These limitations aside, stratification seemed to perform better at lower biomass levels. Increased prediction accuracy, lower RMSE values, and narrow confidence intervals suggest a small improvement with species stratification (Fig. 7).

We tested both linear and non-linear variables for all regression models. Best-fit models were obtained with linear combinations of variables. Although there is an apparent non-linear trend in Fig. 6a and Fig. $6 \mathrm{c}$, it is because of the poor predictive power of the models in low biomass plots ( $<50 \mathrm{Mg} / \mathrm{ha}$ ). The RMSE values from the regression models should be interpreted in terms of model-to-model comparisons rather than an absolute measure of accuracy in a mapping perspective.

Spatial predictions of biomass from LVIS were quite different before and after species stratification by AVIRIS. Relative to specieslevel equations, a single lidar equation underestimated values in the lower ranges and overestimated it in the higher ranges of biomass, particularly for hardwoods and pines. Using a different lidar equation for hardwoods and pines reduced apparent errors in lower ranges of biomass for both these vegetation types (Fig. 9b and d). The trend towards reduced error and improved prediction accuracy was clear (Fig. 7) even at stand level analysis for hardwoods but not for pines.

Fusion of lidar and hyperspectral sensors at species level and in areas with low biomass is an important remote sensing research requirement (Bergen et al., 2006; Rosenqvist et al., 2003; Treuhaft et al., 2004). Our study shows that species stratification could potentially improve predictions from sparse lidar samples, in low biomass regions better than fusion with spectral metrics. More work is needed to confirm these results over larger samples and homogenous stands. Improving classification accuracies for individual species by using field spectra may further refine spatial prediction of biomass from AVIRIS. Also the optimum level of classification (plant functional type, genera or species) and scale ( 1 ha or less) must be studied further.

Intuitively, we would expect species stratification to provide an improvement because the data used for biomass ground truth is routinely derived from forestry tables on a species-level, just as we did in our research here. However, there is the larger, and unanswered question, of whether lidar metrics are sensitive to species-level differences in canopy vertical structure, canopy gap spatial pattern, stem density and stem spatial pattern, among others, that should be predictive of biomass, and at what spatial scales. While speciesspecific predictions as applied in this study could improve estimates over other forested areas, the true impact of a priori stratification may never be known unless this problem is explored thoroughly.

We did not expect a significant change in species composition within the time lag between lidar and hyperspectral data acquisition. However, some uncertainty in spectral metrics related to changes in 

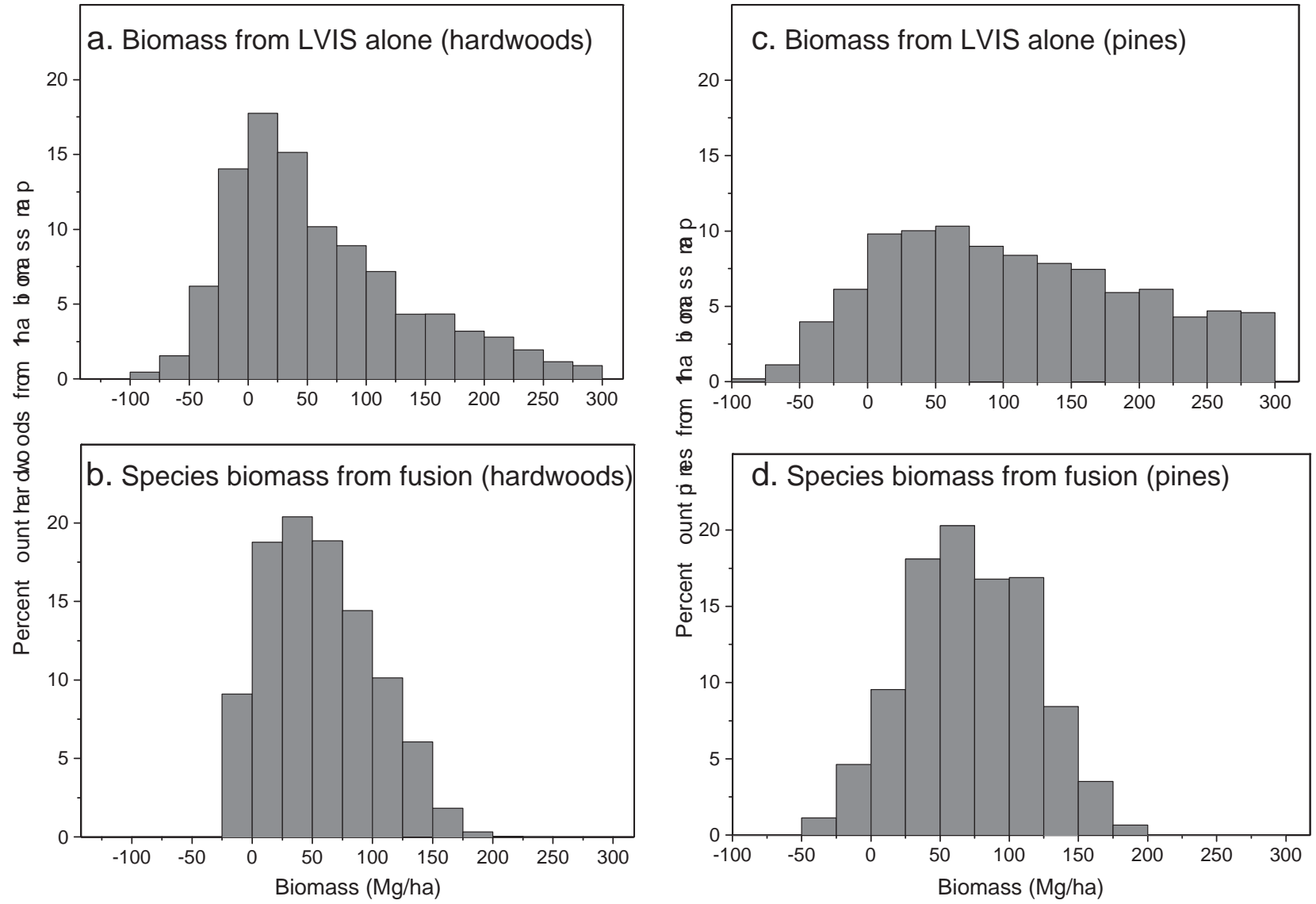

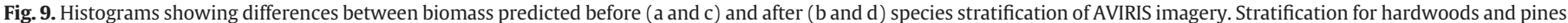
increased predicted values in low ( $<50 \mathrm{Mg} / \mathrm{ha}$ ) ranges and decreased values in high ranges ( $>200 \mathrm{Mg} / \mathrm{ha})$ of biomass.

structure and stress may have affected the outcome. Another limitation was that only large trees $(>76 \mathrm{~cm} \mathrm{dbh})$ were measured in 1 ha plots. Footprint level plots ( $0.07 \mathrm{ha}$ ) included measurements of all trees above
$10 \mathrm{~cm}$ dbh but were not included in this study because of increased geolocation errors between reprocessed LVIS data and 2000/2001 field plot centers. Better geolocation of field, lidar, and hyperspectral data

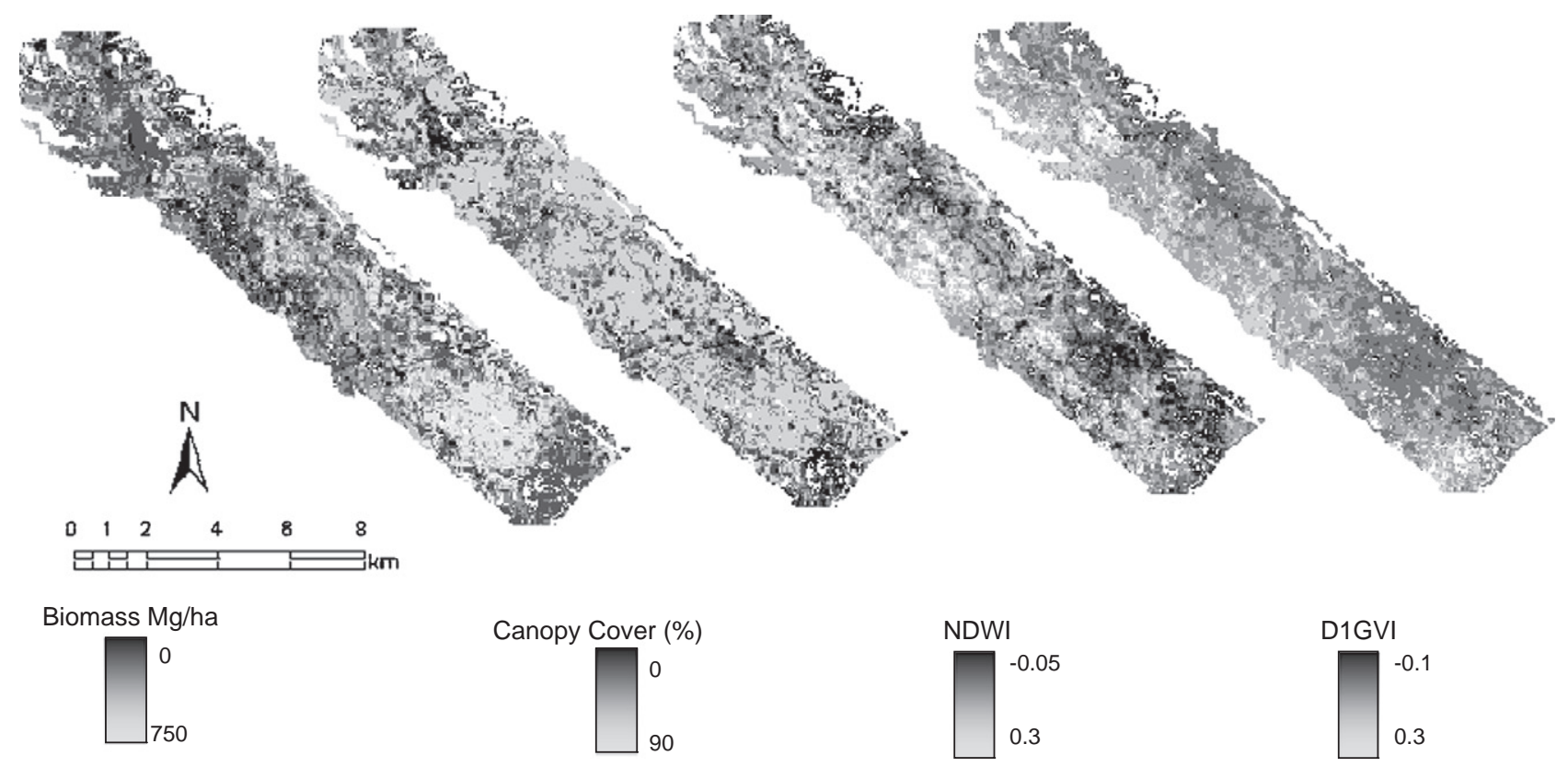

Fig. 10. Landscape maps of biomass, canopy cover, NDWI and D1GVI used for detecting water and chlorophyll stress in high biomass forests. 


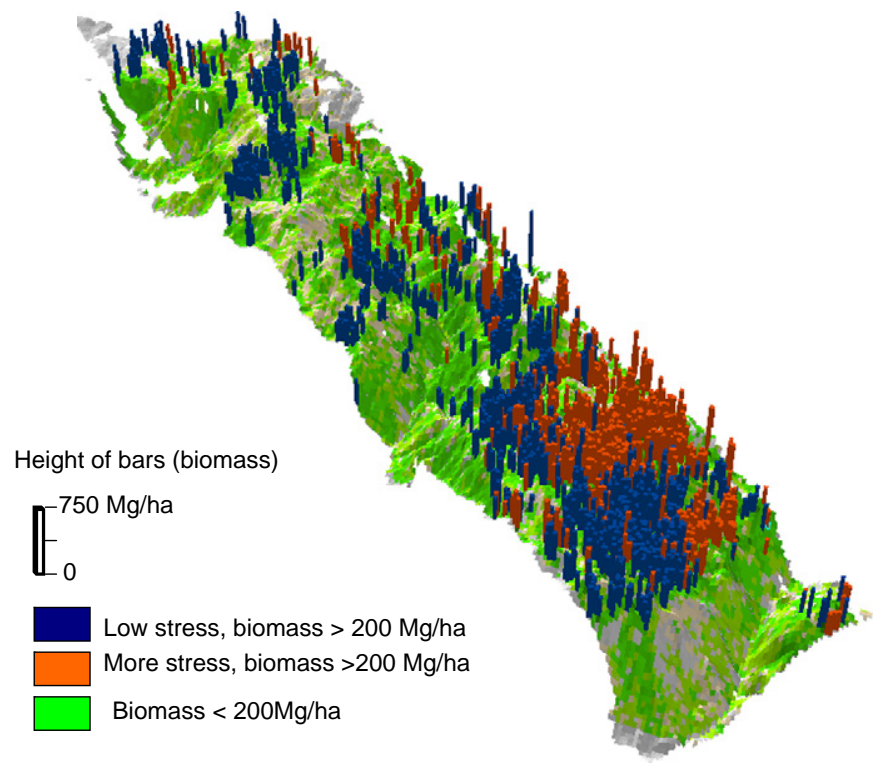

Fig. 11. Map showing high and low stresses in stands with high biomass (>200 Mg/ha). Height of bars represents biomass values.

may help, but this may also only increase correlation between metrics rather than improve biomass estimates.

Spatial maps of various AVIRIS metrics in combination with LVIS maps showed increased water stress in many high biomass red fir $(A$. magnifica) and mixed conifer stands. High values of NPV fractions within canopies in addition to low vegetation and water band indices, suggests increased stress and mortality in these areas. Moisture stress was high in open stands with more canopy gaps as well as in dense stands, consistent with findings from Smith et al. (2005). Our results are similar to recent studies linking water stress and increased tree mortality in the Sierra Nevada (Lutz et al., 2009; Van Mantgem et al., 2009).

Areas within the Teakettle Experimental Forest (North, 2002), where red fir was the dominant vegetation type also showed a large number of NPV spectra in the 2003 AVIRIS images. Subsequent field observations in 2008 showed abundant dead trees as well as evidence of logging in these areas. Further analysis is required to confirm whether stress maps from 2003 AVIRIS images showed early

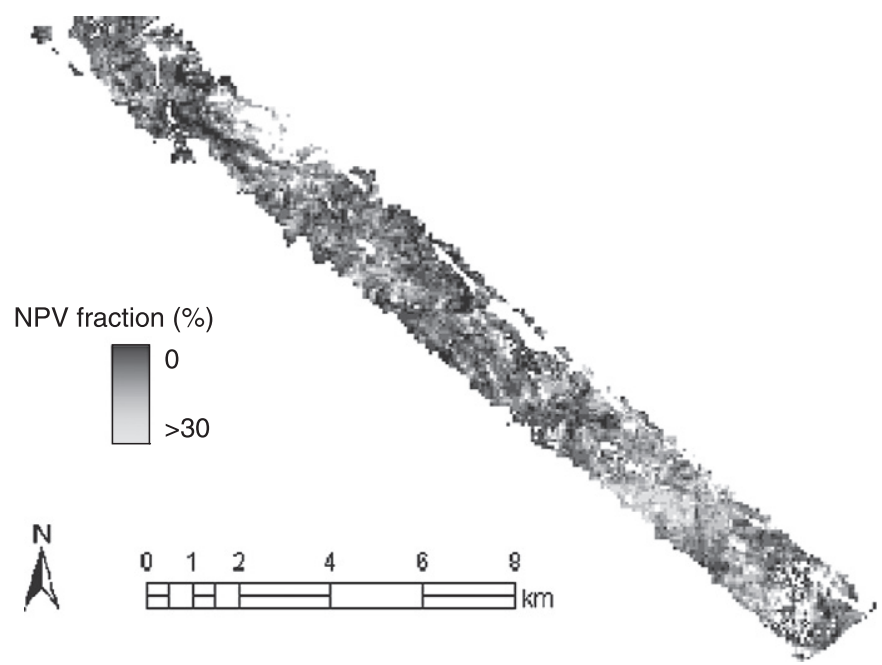

Fig. 12. Spatial distribution of non-photosynthetic vegetation (NPV) fractions within canopies for one AVIRIS image (1 ha level). Stands with high biomass and stress (Fig. 11) also showed high NPV values. indications of the tree mortality observed in 2008. Presumably, lidar/hyperspectral data could be used to map areas of high stress and mortality in response to climate change as suggested by Van Mantgem et al. (2009).

\section{Conclusion}

Species stratification may improve predictions from lidar, a result only suggested by our work, as overall predictive ability did not improve significantly; however, confidence intervals were narrowed and biomass showed very different spatial variability when mapped across the landscape. Extrapolating structure from lidar samples with stratified optical data can be a promising strategy for mapping low biomass forests from future space borne lidar sensors such as DESDynI. Such species-specific biomass maps have the potential to be exceptionally useful for carbon and ecosystem modeling.

AVIRIS indices and MESMA fractions provide quantitative measures of canopy condition and can be of considerable value in ecological applications, when combined with lidar. We demonstrated one such application here, by mapping stress in high biomass forests of Sierra Nevada. Stress maps can serve as early indicators of mortality, drought, and fire susceptibility in old growth forests and help improve forest management practices. Classified vegetation maps can be further used to study regeneration from fire or combined with small footprint lidar data to map individual tree biomass/ mortality.

Lidar can provide measures of vertical structure such as canopy height, understory cover, and foliage diversity while species composition, stress, and decadence can be obtained from hyperspectral data. Fusion of the two sensors is therefore, powerful for biodiversity and habitat studies. Future research will focus on combining the two sensors for mapping potential habitats for rare and endangered bird species.

\section{Acknowledgments}

This research was funded in part by "Multisite Integration of LIDAR and Hyperspectral Data for Improved Estimation of Carbon Stocks and Exchanges" (P.I. Dar Roberts), NASA Carbon Cycle Science grant (NNG05GE56G) and a NASA Earth and Space Science graduate fellowship (NNX06AF91H). Error matrix codes for assessing accuracy of MESMA models were made available by Phillip Dennsion. We are thankful to Kerry Halligan, Dylan Parenti and the Viper Lab team at University of California, Santa Barbara for software training and help with AVIRIS data processing. We thank Peter Hyde for providing useful inputs from previous studies in the Sierra Nevada.

\section{References}

Adams, J. B., Smith, M. O., \& Johnson, P. E. (1986). Spectral mixture modeling: A new analysis of rock and soil types at the Viking Lander 1 site. Journal of Geophysical Research, 91(B8), 8090-8112.

Anderson, J. E., Martin, M. E., Smith, M. L., Dubayah, R. O., Hofton, M., Hyde, P., et al. (2005). The use of waveform lidar to measure northern temperate mixed conifer and deciduous forest structure in New Hampshire. Remote Sensing of Environment, 105(3), 248-261.

Anderson, J. E., Plourde, L. C., Martin, M. E., Braswell, B. H., Smith, M. L., Dubayah, R. O. et al. (2008). Integrating waveform lidar with hyperspectral imagery for inventory of a northern temperate forest. Remote Sensing of Environment: Remote Sensing Data Assimilation Special Issue, 112(4), 1856-1870.

Asner, G. P. (1998). Biophysical and biochemical sources of variability in canopy reflectance. Remote Sensing of Environment, 64(3), 234-253.

Asner, G. P., Knapp, D. E., Kennedy-Bowdoin, Ty, Jones, M. O., Martin, R. E., Boardman, J., et al. (2008). Invasive species detection in Hawaiian rainforests using airborne imaging spectroscopy and LiDAR. Remote Sensing of Environment, 112(5), 1942-1955.

Bergen, K. M., Gilboy, A. M., \& Brown, D. G. (2007). Multi-dimensional vegetation structure in modeling avian habitat. Ecological Informatics, 2(1), 9-22.

Multi-dimensional forested ecosystem structure: Requirements for remote sensing observations. Bergen, K. M., Knox, R. G., \& Saatchi, S. (Eds.). (2006). NASA/CP2005-212778. Washington, D.C.: NASA GSFC 36 pp.. 
Blair, J. B., Hofton, M. A., \& Rabine, D. L. (2006). Processing of NASA LVIS elevation and canopy (LGE, LCE, and LGW) data products, version 1.01. http://lvis.gsfc.nasa.gov

Blair, J. B., Rabine, D. L., \& Hofton, M. A. (1999). The Laser Vegetation Imaging Sensor (LVIS): A medium-altitude, digitization-only, airborne laser altimeter for mapping vegetation and topography. ISPRS Journal of Photogrammetry and Remote Sensing $54,115-122$.

Chambers, J. Q., Asner, G. P., Morton, D. C., Anderson, L. O., Saatchi, S. S., Fernando, D. B. et al. (2007). Regional ecosystem structure and function: Ecological insights from remote sensing of tropical forests. Trends in Ecology E' Evolution, 22(8), 414-423.

Clark, M. L., Clark, D. B., \& Roberts, D. A. (2004). Small-footprint lidar estimation of subcanopy elevation and tree height in a tropical rain forest landscape. Remote Sensing of Environment, 91(1), 68-89.

Clark, M. L., Roberts, D. A., \& Clark, D. B. (2005). Hyperspectral discrimination of tropical rain forest tree species at leaf to crown scales. Remote Sensing of Environment, 96(3-4), 375-398.

Curran, P. J., Dungan, J. L., \& Peterson, D. L. (2001). Estimating the foliar biochemical concentration of leaves with reflectance spectrometry testing the Kokaly and Clark methodologies. Remote Sensing of Environment, 76(3), 349-359.

Dennison, P. E., Halligan, K. Q., \& Roberts, D. A. (2004). A comparison of error metrics and constraints for multiple endmember spectral mixture analysis and spectral angle mapper. Remote Sensing of Environment, 93(3), 359-367.

Dennison, P. E., \& Roberts, D. A. (2003). Endmember selection for multiple endmember spectral mixture analysis using endmember average RMSE. Remote Sensing of Environment, 87(2-3), 123-135.

Drake, J. B., Dubayah, R. O., Clark, D. B., Knox, R. G., Blair, J. B., Hofton, M. A., et al. (2002a). Estimation of tropical forest structural characteristics using largefootprint lidar. Remote Sensing of Environment, 79(2-3), 305-319.

Drake, J. P., Dubayah, R., Knox, R. G., Clark, D. B., \& Blair, J. B. (2002b). Sensitivity of largefootprint lidar to canopy structure and biomass in a neotropical rainforest. Remote Sensing of Environment, 81(2-3), 378-392.

Dubayah, R. O., Knox, R. G., Hofton, M. A., Blair, J. B., \& Drake, J. B. (2000). Land surface characterization using lidar remote sensing. In M. J. Hill, \& R. J. Aspinall (Eds.) Spatial information for land use management (pp. 25-38). Australia: Gordon and Breach Science Publishers.

Elvidge, C. D., \& Chen, Z. (1995). Comparison of broad-band and narrow-band red and near-infrared vegetation indices. Remote Sensing of Environment, 54(1), 38-48.

Franke, J., Roberts, D. A., Halligan, K., \& Menz, G. (2009). Hierarchical Multiple Endmember Spectral Mixture Analysis (MESMA) of hyperspectral imagery for urban environments. Remote Sensing of Environment, 113(8), 1712-1723.

Gao, B. C. (1996). NDWI-A normalized difference water index for remote sensing of vegetation liquid water from space. Remote Sensing of Environment, 58(3), 257-266.

Gitelson, A. A., Kaufman, Y. J., Stark, R., \& Rundquist, D. (2002). Novel algorithms for remote sensing estimation of vegetation fraction. Remote Sensing of Environment, $80(1), 76-87$.

Green, R. O., Conel, J. E., \& Roberts, D. A. (1993). Estimation of aerosol optica1 depth and additional atmospheric parameters for the calculation of apparent reflectance from radiance measured by the Airborne Visible/Infrared Imaging Spectrometer. Summaries of the Fourth Annual JPL Airborne Geoscience Workshop, Oct 25-29, 1993. AVIRIS Workshop, Washington, DC, Vol. 1. (pp. 73-76).

Green, R. O., Eastwood, M. L., Sarture, C. M., Chrien, T. G., Aronsson, M., Chippendale, B. J. et al. (1998). Imaging spectroscopy and the Airborne Visible/Infrared Imaging Spectrometer (AVIRIS). Remote Sensing of Environment, 65(3), 227-248.

Hese, S., Lucht, W., Schmullius, C., Barnsley, M., Dubayah, R., Knorr, D., et al. (2005). Global biomass mapping for an improved understanding of the $\mathrm{CO} 2$ balance? The Earth observation mission Carbon-3D. Remote Sensing of Environment, 94(1), 94-104.

Hofton, M. A., \& Blair, J. B. (2002). Laser altimeter return pulse correlation: A method for detecting surface topographic change. Journal of Geodynamics, 34(3-4), 477-489.

Houghton, R. A. (2005). Aboveground forest biomass and the global carbon balance. Global Change Biology, 11, 945-958.

Hudak, A. T., Lefsky, M. A., Cohen, W. B., \& Berterretche, M. (2002). Integration of lidar and LANDSAT ETM+ data for estimating and mapping forest canopy height. Remote Sensing of Environment, 82(2-3), 397-416.

Huete, A. R., Liu, HuiQing, \& van Leeuwen, W. J. D. (1997). The use of vegetation indices in forested regions: Issues of linearity and saturation. Geoscience and Remote Sensing, IGARSS '97. Remote Sensing - A Scientific Vision for Sustainable Development 1997 IEEE International.

Hunsaker, C. T., Boroski, B. B., \& Steger, G. N. (2002). Relations between canopy cover and occurrence and productivity of California spotted owls, predicting species occurrences, issues of accuracy and scale. Covelo, CA: Island Press.

Hyde, P., Dubayah, R., Peterson, B., Blair, J. B., Hofton, M., \& Hunsaker, C. (2005) Mapping Forest Structure for Wildlife Habitat Analysis using Waveform Lidar: validation of montane ecosystems. Remote Sensing of Environment, 96(3-4), 427-437.

Hyde, P., Dubayah, R., Walker, W., Blair, J. B., Hofton, M., \& Hunsaker, C. (2007a). Mapping forest structure for wildlife habitat analysis using multi-sensor (Lidar SAR/InSAR, ETM+, Quickbird) synergy. Remote Sensing of Environment, 102(1-2) 63-73.

Hyde, P., Nelson, R., Kimes, D., \& Levine, E. (2007b). Exploring LiDAR-RaDAR synergypredicting aboveground biomass in a southwestern ponderosa pine forest using LiDAR, SAR and InSAR. Remote Sensing of Environment, 106(1), 28-38.

Jordan, C. F. (1969). Derivation of leaf area index from quality of light on the forest floor. Ecology, 50, 663-666.

Keith, H., Mackey, B. G., \& Lindenmayer, D. B. (2009, July 14). Re-evaluation of forest biomass carbon stocks and lessons from the world's most carbon-dense forests. PNAS, 106(28).
Kimes, D. S., Ranson, K. J., Sun, G., \& Blair, J. B. (2006). Predicting lidar measured forest vertical structure from multi-angle spectral data. Remote Sensing of Environment, 100(4), 503-511.

Koetz, B., Sun, G., Morsdorf, F., Ranson, K. J., Kneubühler, M., Itten, K., et al. (2007). Fusion of imaging spectrometer and LIDAR data over combined radiative transfer models for forest canopy characterization. Remote Sensing of Environment, 106(4), 449-459.

Kokaly, R. F., \& Clark, R. N. (1999). Spectroscopic determination of leaf biochemistry using band-depth analysis of absorption features and stepwise multiple linear regression. Remote Sensing of Environment, 67(3), 267-287.

Lefsky, M. A., Cohen, W. B., Parker, G. G., \& Harding, D. J. (2002). Lidar remote sensing for ecosystem studies. Bioscience, 52(1), 19-30.

Lutz, J. A., van Wagtendonk, J. W., \& Franklin, J. F. (2009). Twentieth-century decline of large-diameter trees in Yosemite National Park, California, USA. Forest Ecology and Management, 257(11), 2296-2307.

Maki, M., Ishiahra, M., \& Tamura, M. (2004). Estimation of leaf water status to monitor the risk of forest fires by using remotely sensed data. Remote Sensing of Environment, 90, 441-450.

Martin, M. E., Newman, S. D., Aber, J. D., \& Congalton, R. G. (1998). Determining forest species composition using high spectral resolution remote sensing data. Remote Sensing of Environment, 65, 249-254.

Mayer, K. E., \& Laudenslayer, W. F. (Eds.). (1988). A guide to the wildlife habitats of California. Sacramento, CA: California Dept of Forestry and Fire Protection.

Merton, R. N. (1998). Monitoring community hysteresis using spectral shift analysis and the red-edge vegetation stress index. Proceedings of the Seventh JPL Airborne Earth Science Workshop (pp. 275-284). Pasadena, CA: Jet Propulsion Laboratory.

Mundt, J., Streutker, D. R., \& Glenn, N. F. (2006). Mapping sagebrush distribution using fusion of hyperspectral and lidar classifications. Photogrammetric Engineering and Remote Sensing (PEERS), 72, 47-54.

Ni Meister, W., Dubayah, R., \& Jupp, D. (2001). Modeling lidar waveforms in heterogeneous and discrete canopies. IEEE Transactions on Geoscience and Remote Sensing, 39(9), 1943-1958.

North, M. P. (2002). The Teakettle Experiment 1 Teakettle's Role in the Kings River. Sierra, 47-54.

Numata, I., Roberts, D. A., Chadwick, O. A., Schimel, J. P., Galvao, L. S., \& Soares, J. V. (2008). Evaluation of hyperspectral data for pasture estimate in the Brazilian Amazon using field and imaging spectrometers. Remote Sensing of Environment, 112(4), 1569-1583.

Peñuelas, J., Filella, I., Biel, C., Serrano, L., \& Savé, R. (1993). The reflectance at the 950$970 \mathrm{~nm}$ region as an indicator of plant water status. International Journal of Remote Sensing, 14(10), 1887-1905

Pierce, L. E., Walker, W. S., Dobson, M. C., Hunsaker, C. T., Fites-Kauftnan, J. A., \& Dubayah, R. (2002). Fusion of optical and SAR data for forestry applications in the Sierra Nevada of California. Geoscience and Remote Sensing Symposium, IGARSS '02, IEEE International.

Pu, R., Gong, P., Biging, G. S., \& Larrieu, M. R. (2003). Extraction of red edge optical parameters from Hyperion data for estimation of forest leaf area index. IEEE Transactions on Geoscience and Remote Sensing, 41(4), 916-921.

Roberts, D. A., Dennison, P. E., Gardner, M., Hetzel, Y., Ustin, S. L., \& Lee, C. (2003). Evaluation of the potential of Hyperion for fire danger assessment by comparison to the Airborne Visible/Infrared Imaging Spectrometer. IEEE Transactions on Geoscience and Remote Sensing, 41(6), 1297-1310.

Roberts, D. A., Dennison, P. E., Peterson, S., Sweeney, S., \& Rechel, J. (2006). Evaluation of AVIRIS and MODIS measures of live fuel moisture and fuel condition in a shrubland ecosystem in Southern California. J. Geophysical. Res. Biogeosciences, 111.

Roberts, D. A., Gardner, M., Church, R., Ustin, S., Scheer, G., \& Green, R. O. (1998). Mapping chaparral in the Santa Monica Mountains using multiple endmember spectral mixture models. Remote Sensing of Environment, 65, 267-279.

Roberts, D. A., Green, R. O., \& Adams, J. B. (1997). Temporal and spatial patterns in vegetation and atmospheric properties from AVIRIS. Remote Sensing of Environment, 62(3), 223-240.

Roberts, D., Halligan, K., \& Dennison, P. (2007). VIPER Tools User Manual. http://www. vipertools.org/ Santa Barbara

Roberts, D. A., Ustin, S. L., Ogunjemiyo, S., Greenberg, J., Dobrowski, S. Z., Chen, J., et al. (2004). Spectral and structural measures of Northwest forest vegetation at leaf to landscape scales. Ecosystems, 7, 545-562.

Rosenqvist, A., Milne, A., Lucas, R., Imhoff, M., \& Dobson, C. (2003). A review of remote sensing technology in support of the Kyoto protocol. Environmental Science \& Policy, 6(5), 441-455.

Roth, K. L. (2009). A combined lidar and hyperspectral remote sensing analysis for mapping forest biomass. Unpublished masters thesis. University of California, Santa Barbara, Dept of Geography.

Serrano, L., Ustin, S. L., Roberts, D. A., Gamon, J. A., \& Penuelas, J. (2000). Deriving water content of Chaparral Vegetation from AVIRIS data. Remote Sensing of Environment, $74(3), 570-581$.

Smith, K. (2004). Use of hyperspectral derivative ratios in the red-edge region to identify plant stress responses to gas leaks. Remote Sensing of Environment, 92(2), 207-217.

Smith, T. F., Rizzo, D. M., \& North, M. (2005). Patterns of mortality in an old-growth mixedconifer forest of the Southern Sierra Nevada, California. Forest Science, 51(3), 266-275.

Sonnetag, O., Chen, J. M., Roberts, D. A., Talbot, J., Halligan, K. Q., \& Govind, A. (2007). Mapping tree and shrub leaf area indices in an ombrotrophic peatland through multiple endmember spectral unmixing. Remote Sensing of Environment, 109, 342-360.

Treuhaft, R., Law, B. E., \& Asner, G. P. (2004). Forest attributes from radar interferometric structure and its fusion with optical remote sensing. Bioscience, 54(6), 561-571. 
Tucker, C. J. (1979). Red and photographic infrared linear combinations for monitoring vegetation. Remote Sensing of Environment, 8, 127-150.

Ustin, S. L., Roberts, D. A., Gamon, J. A., Asner, G. P., \& Green, R. O. (2004). Using imaging spectroscopy to study ecosystem processes and properties. Bioscience, 54(6), 523-534

Van Mantgem, P. J., Stephenson, N. L., Byrne, J. C., Daniels, L. D., Franklin, J. F., Fulé, P. Z., et al. (2009). Widespread increase of tree mortality rates in the Western United States. Science, 323(5913), 521-524.
Waddell, K., \& Hiserote, B. (2003). Technical documentation for the integrated database, version 1.0. USDA Forest Service Pacific Northwest Research Station.

Zald, H. S., Gray, A. N., North, M., \& Kern, R. A. (2008). Initial tree regeneration responses to fire and thinning treatments in a Sierra Nevada mixed-conifer forest, USA. Forest Ecology and Management, 256(1-2), 168-179. 